\title{
MICROHOLE WIRELESS STEERING WHILE DRILLING SYSTEM
}

\section{FINAL TECHNICAL REPORT}

Report Period Start Date: February 1, 2005

Report Period End Date: December 31, 2007

$\begin{array}{ll}\text { Authors: } & \text { John Macpherson } \\ & \text { Thomas Gregg }\end{array}$

REPORT DATE: March 27, 2008

\section{DOE AWARD NUMBER: DE-FC26-05NT15488}

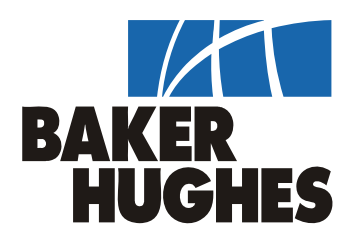

Baker Hughes Oilfield Operations, Inc.

3900 Essex lane, Suite 1200,

Houston, Texas 77027-5170 


\section{DISCLAIMER}

This report was prepared as an account of work sponsored by an agency of the United States Government. Neither the United States Government, nor any of their employees, makes any warranty, express or implied, or assumes any legal liability or responsibility for the accuracy, completeness, or usefulness of any information, apparatus, product, or process disclosed, or represents that its use would not infringe owned rights. Reference herein to any specific commercial product, process, or service by trade name, trademark, manufacturer, or otherwise does not necessarily constitute or imply its endorsement, recommendation, or favoring by the United States Government or any agency thereof. The views and opinions of authors expressed herein do not necessarily state or reflect those of the United States Government or any agency thereof. 


\section{Abstract}

A background to Coiled Tubing Bottom Hole Assemblies (CT-BHA) is given, and the development of a bi-directional communications and power module (BCPM)component is described. The successful operation of this component in both the laboratory and field environment is described. The primary conclusion of this development is that the BCPM component operates as anticipated within the CT-BHA, and significantly extends the possibility of drilling with coiled tubing in the microhole environment.

\section{Table of Contents}

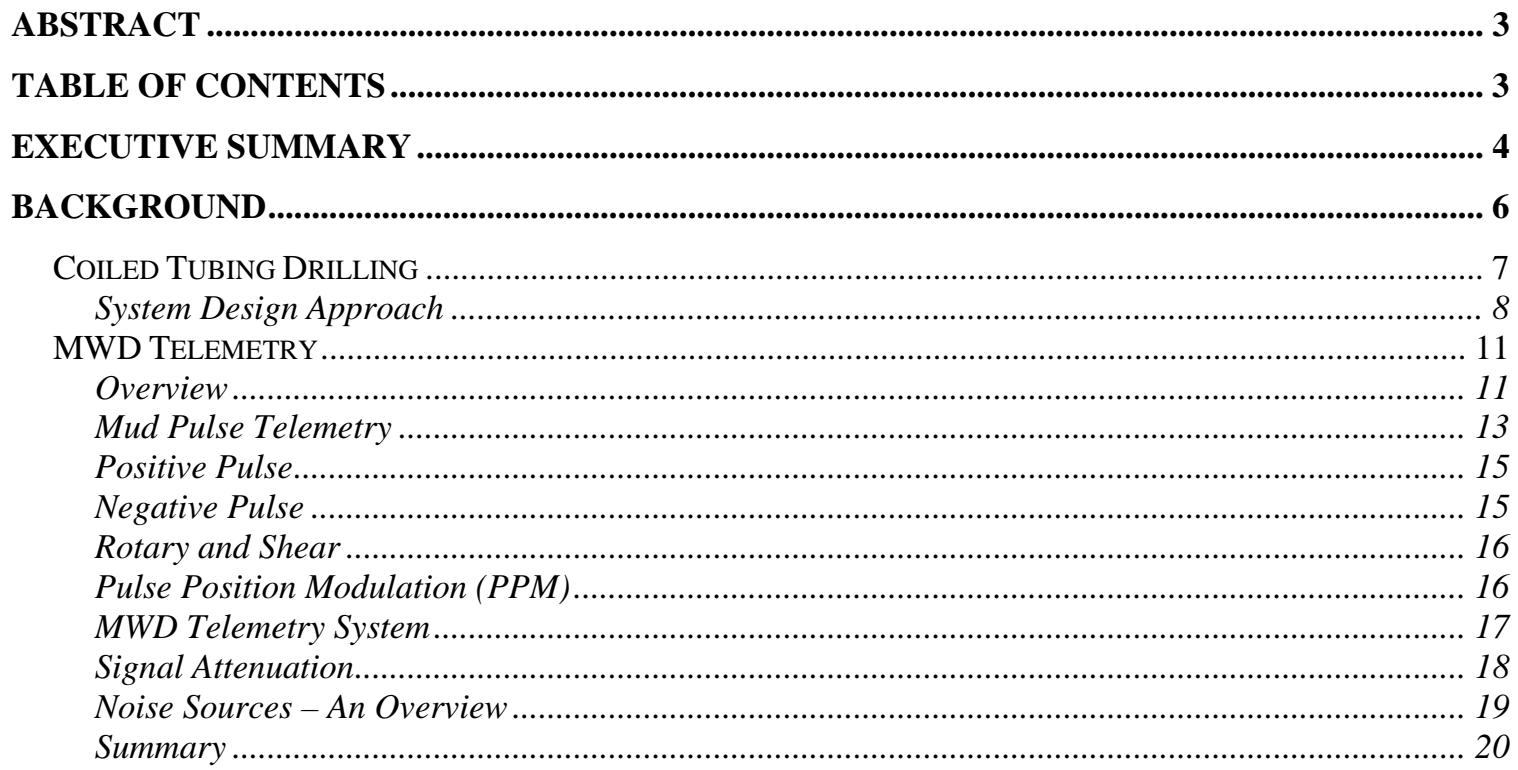

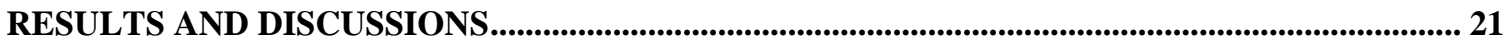

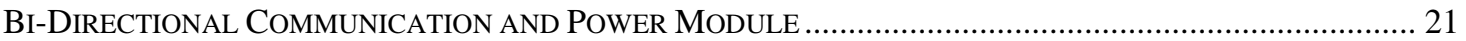

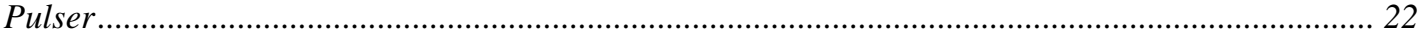

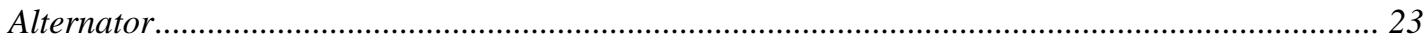

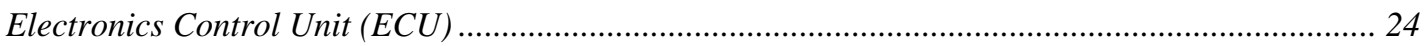

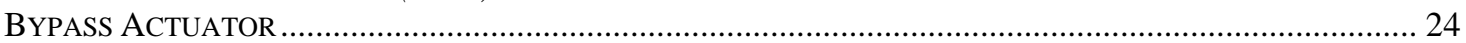

LABORATORY AND PRELIMINARY INTEGRATION TESTING, 2-3/8” BCPM ……........................................ 26

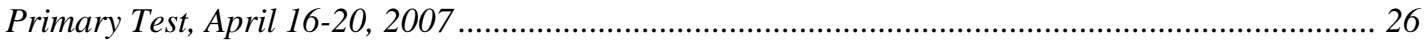

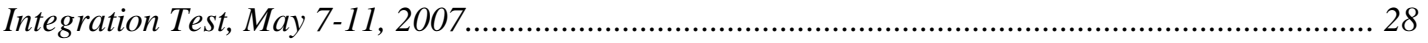

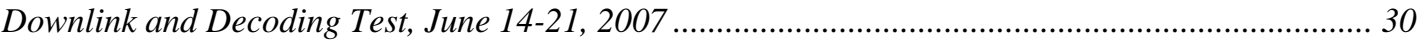

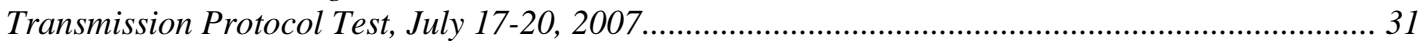

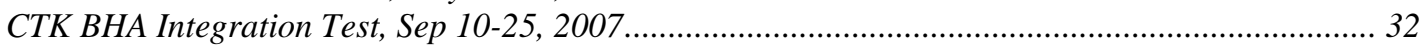

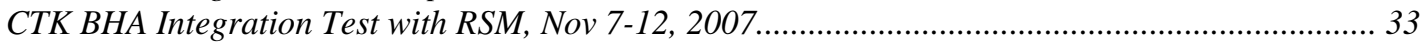

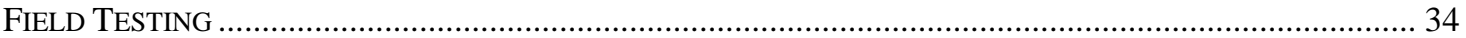

Baker Hughes Experimental Test Area …………....................................................................... 34

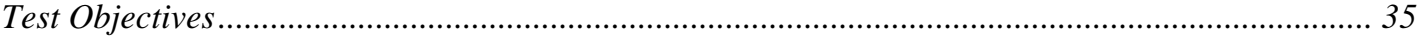

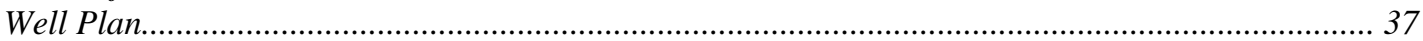

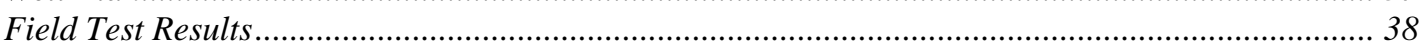

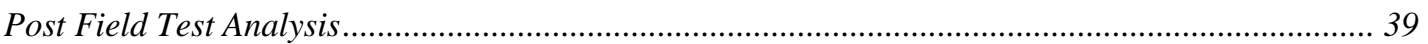

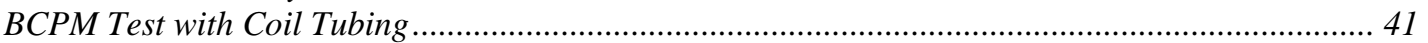

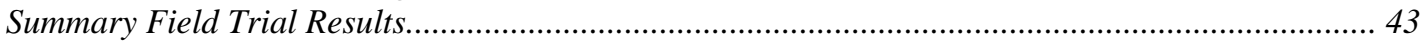

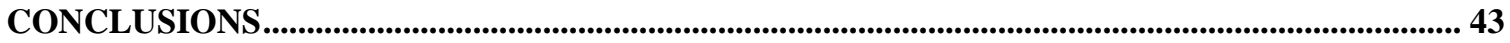




\section{Executive Summary}

Baker Hughes INTEQ and the Department of Energy are engaged in cooperative agreement DE-FC26-05NT15488 to develop a Microhole Wireless Steering While Drilling System. Microhole technology focuses on developing drilling systems to tap into the large reserves that occur at shallow depths in the U.S., and which are considered nonrecoverable with the current drilling technology. Targets of microhole drilling systems are borehole sizes of 3-1/2" or smaller and vertical depths of less than 5,000 feet.

The objective of the Microhole Wireless Steering While Drilling System project is to design and build devices to provide wireless communication and power for existing 23/8” Coiled Tubing BHAs. The system consists of two components:

- A Bi-Directional Communication and Power Module (BCPM): The BCPM generates electric power downhole through conversion of the hydraulic mud energy using a turbine driven alternator. The BCPM also contains a mud pressure pulser device that generates signals by creating a momentary mud flow restriction - these signals propagate to surface and uplink downhole data. Finally, surface initiated mud flow modulation can be detected downhole in the BCPM, thereby receiving commands and data from the surface.

- A Bypass Control Actuator (BPA): The BPA downlinks information from surface to downhole by diverting fluid on surface and creating a sequence of flow rate changes which are detected by the BCPM downhole. While Baker Hughes INTEQ had previously developed the Bypass Control Actuator for use with its standard MWD tools strings, it was necessary to modify the fluid handling characteristics of the device in order for it to operate with the $23 / 8$ ” system.

Three prototypes of the BCPM were built. These were initially laboratory tested in the Baker Hughes Flow Loop in Houston and then at the Baker Hughes Test Facility in Beggs, Oklahoma. At the Oklahoma test facility, all 3 prototypes were run downhole in a conventional drillstring. In order to validate performance when operating with coil tubing, a final test was conducted using a 7,000 foot coil in the Baker Hughes Flow Loop in Houston. While the details of these tests are contained in this report, the highlights are as follows:

- The prototypes were individually tested in the Flow Loop and their target upper and lower operating limits were validated.

- The prototypes were successfully integration tested in the target CoilTrak ${ }^{\mathrm{TM}}$ BHA at the Baker Hughes Flow Loop Test Facility without any major problems.

- While the test was not ideal due to the use of a conventional drill-string rather than coiled tubing, the tools functioned while drilling in the Test Well at Baker Hughes' Oklahoma facility,

- The final test in the Baker Hughes Test Facility proved that the system functioned extremely well throughout its specified operating range when run through a 7000 ft coil. 
Baker Hughes INTEQ is extremely pleased with the performance of these prototype tools, and intends to run them again to gain operating time and footage. It will then re-evaluate the design, and make a decision on full commercialization of these components.

U.S. Department of Energy participation in funding of this project has been critical to its success. Without this participation, it is likely that significant delays in the development of these critical BHA components for microhole drilling would have occurred. 


\section{Background}

The technology developed in this cooperative agreement targeted the specific problem of utilizing the most advanced steering technology under microhole drilling conditions in areas where the coil tubing cannot be economically furnished with an electric line.

For the drilling of 3-1/2" or smaller diameter development wells, coiled tubing technology offers many benefits over rotary drilling. However, since Coiled Tubing Drilling (CTD) is a niche market, service companies are restricted in funds for new coiled tubing Bottom-Hole Assembly (BHA) development.

A typical state of the art BHA uses a downhole mud motor with an Adjustable Kick-Off (AKO) sub and an electric motor driven angle adjustment device. Even though such a system can be used to kick off from the previous vertical hole section into the build section, such assemblies tend to produce a non-steady borehole curvature. This results in considerable dog legs and hole tortuosity, which in turn lead to higher friction when sliding the coil, and thus limits the maximum horizontal extension that can be drilled with such equipment. A recently initiated project that was co-funded by the DOE - NT15473 - overcame this constraint by providing a Rib Steering device in conjunction with an integral high-performance downhole motor (RSM). Such a module produced a very smooth borehole curvature and was able to extend the hole length beyond the previous capabilities in the $3 \frac{1 / 2}{2}$ " hole size. The one limitation to applying this new technology is due to the need to have an electric wire in the coiled tubing. This electric wire is used to both provide power to the steering tool, and for downhole to surface communication. In cases where a wired coil means too high an effort or expenditure, the microhole drilling operation cannot utilize the new steering capabilities.

The bi-directional communications and power module developed as part of this project overcomes this constraint by providing a downhole component for a 2-3/8” BHA that is capable of providing electrical power, sending data from downhole to surface, and receiving control information from surface, all using the drilling fluid. 


\section{Coiled Tubing Drilling}

Coiled tubing drilling is, in general, a proven and mature technology that competes successfully against conventional rotary drilling, if the technical and economical aspects of the application fit the characteristics of the coiled tubing system.

"In 1991, open-hole drilling with coiled tubing (except for some work performed in the 1970s) began. The number of wells drilled with coiled tubing since those three initial wells in 1991 has increased sharply. Though the numbers of wells involved is still relatively small compared to the total drilling market, the potential of CT drilling makes it a very exciting service." ${ }^{1}$

Baker Hughes INTEQ has had a long tradition in developing, manufacturing and operating coiled tubing drilling assemblies since the early 90s of the last century. In 1991 Baker Hughes INTEQ actually started the research and development of the world's first E-line CT drilling prototype BHA system called OrientXPress (OXP), which evolved into the current CoilTrak ${ }^{\mathrm{TM}}$ BHA system.

Over the years, INTEQ has developed the industry standard for CT drilling and has gained valuable experience in major worldwide re-entry drilling projects, both in under balanced and overbalanced drilling. The following are a few of INTEQ's Coiled Tubing Drilling milestones:

1992 First pilot series run to verify concept of CT orienting tool

1995 OrientXPress successfully drilled well at $265^{\circ} \mathrm{F}$ (130 C) in Holland

1998 Development of ultra slim (3 1/8”) resistivity (MPR) for CT Drilling

1999 Successfully ran first commercial Ultra Slim LWD geosteering

2000 Record longest horizontal section drilled with CT in Oman of 4,677 ft (1,425 m).

2001 Initial field tests of first E-line operated 2 3/8” CoilTrak

2002 Introduction of the 2 3/8" CoilTrak and 2 3/8” X-treme motors

2003 Introduction of the 3 ” CoilTrak in UB two-phase flow and $300^{\circ} \mathrm{F}(150 \mathrm{C})$ downhole temperature

2006 Development of 2-3/8” resistivity (MPR) and rib-steering motor (RSM) for CT Drilling. Partially funded by DOE/NETL.

Even though there are other vendors of coiled tubing drilling bottom-hole assemblies, Baker Hughes INTEQ (BHI) is the leading provider of such equipment and services. BHI through the last 10 years has moved from its early OrientXPress ${ }^{\mathrm{TM}}$ to the state-of-the-art modular CoilTrak ${ }^{\mathrm{TM}}$ system.

${ }^{1}$ Ken Newman, World Oil, Jan. 1998 
The CoilTrak ${ }^{\mathrm{TM}}$ BHA system is designed to both drill and evaluate holes. CoilTrak ${ }^{\mathrm{TM}}$ comes in two sizes: 2-3/8” and 3". The first size is used to drill a 2-3/4" - 3-1/2” hole, whereas the latter size is for the $3-1 / 2$ " to $4-3 / 4$ " hole size. The bottom-hole assembly, which currently transmits data on a wireline inside the coiled tubing, can measure directional, gamma ray, resistivity and temperature data. Additional features can include weight on bit, annular and bore pressure.

Baker Hughes markets the NaviDrill ${ }^{\circledR}$ motor in different versions for CTD applications. In both cases, downhole steering is accomplished by means of a mud motor with integrated adjustable kick-off (AKO) sub. A 3-1/8” ultra-slim multi-propagation resistivity (US MPR) formation evaluation sub is available for the larger tool size version only.

\section{System Design Approach}

The current 2 3/8” CoilTrak bottom hole assembly shown below in Figure 1 is steered by the Rib Steering Motor, which is controlled by the Hydraulic Power Control Sub. The signal and electrical power for the Hydraulic Sub are actually generated at the surface and linked to the BHA via the Power and Communication Sub as shown in the schematic.

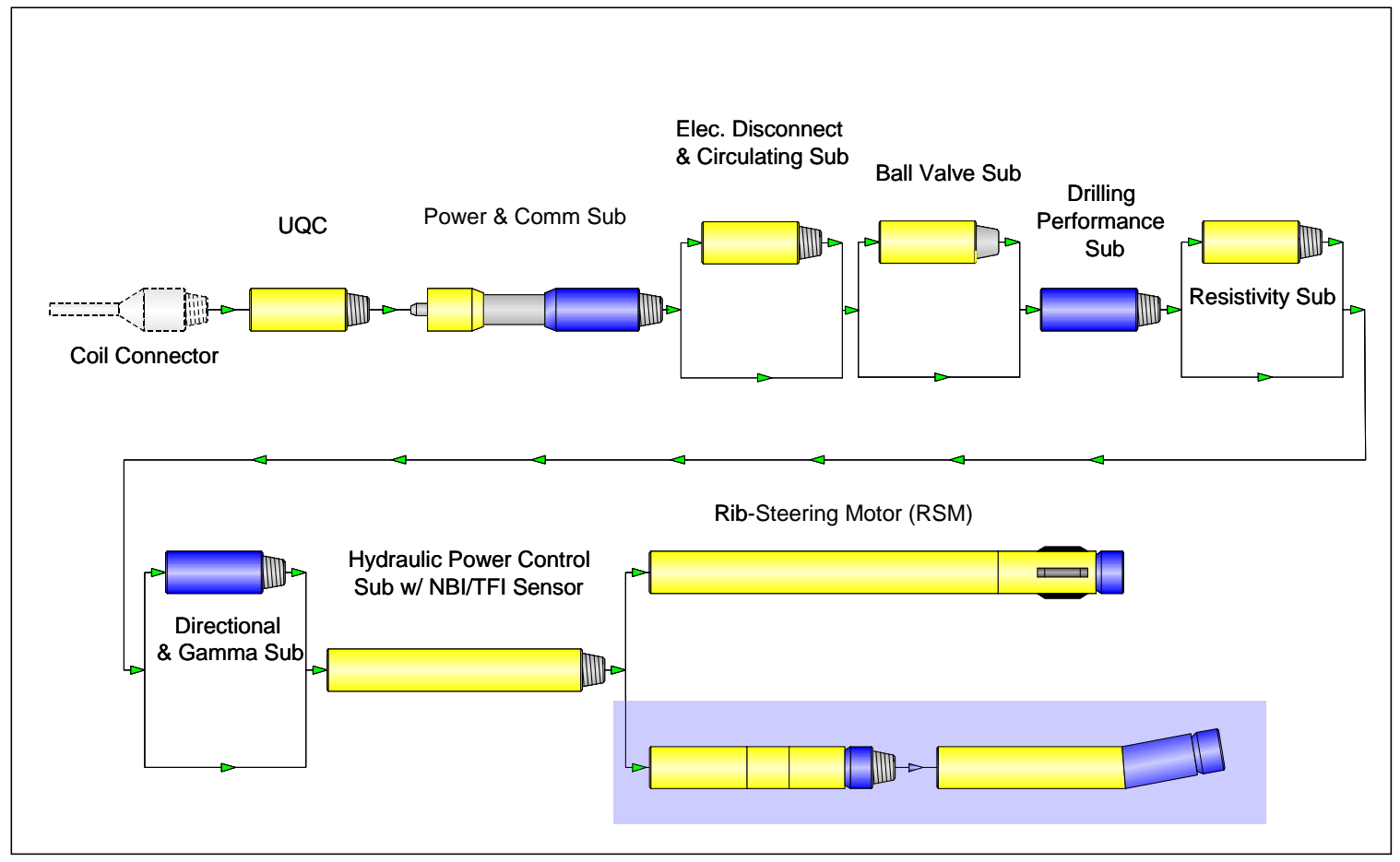

Figure 1: Current 2-3/8” CoilTrak BHA with Rib Steering Motor and Electric Power and Communication Line

In order to run the equipment illustrated in Figure 1, it is a requirement to have coil tubing available that is furnished with an electric cable. In many cases this limits operational flexibility, because cable-less coils are easier to provide and cheaper to 
operate. In addition, the reduction in the internal diameter caused by the cable means a higher flow restriction, which technically constrains the operational envelope.

The CoilTrak bottom hole assembly proposed in this project provides an alternative: drilling without an electric cable. As with conventional drilling using jointed drillpipe, the mud flow inside the drill string will be utilized as an energy source for the downhole electrical devices, and as a bi-directional communication channel. Such alternative CoilTrak BHAs do not require the cable-based tool modules illustrated in Figure 1. Instead, one power and communication module is used to convert the mud energy and pressure fluctuation into the required electrical energy and signal information. In this case the BHA will look like that shown in Figure 2.

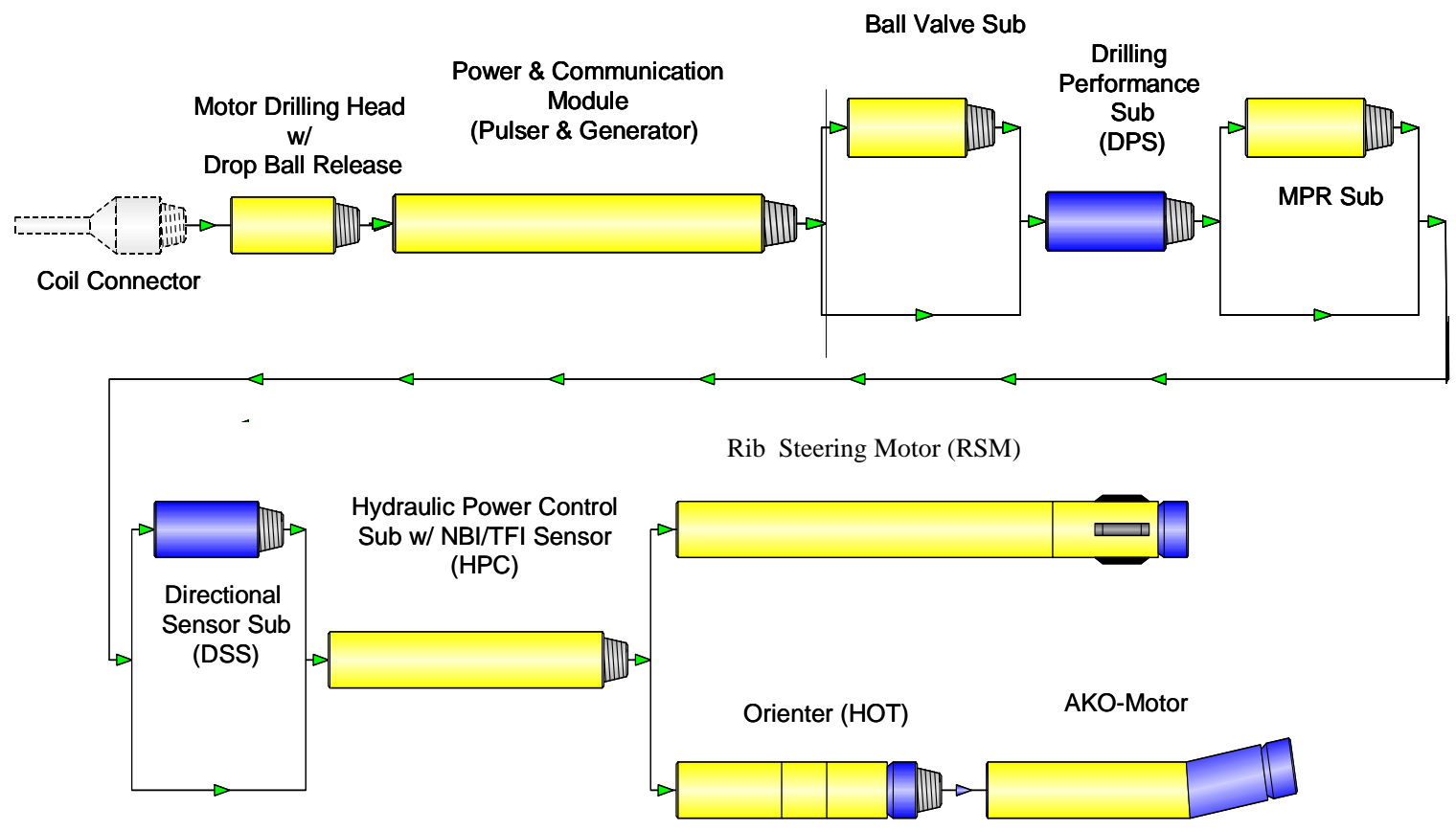

Figure 2: New 2 3/8” CoilTrak BHA with Mud Power and Communication

An additional example of the lower part of the BHA combined with the BCPM is shown in Figure 3. 


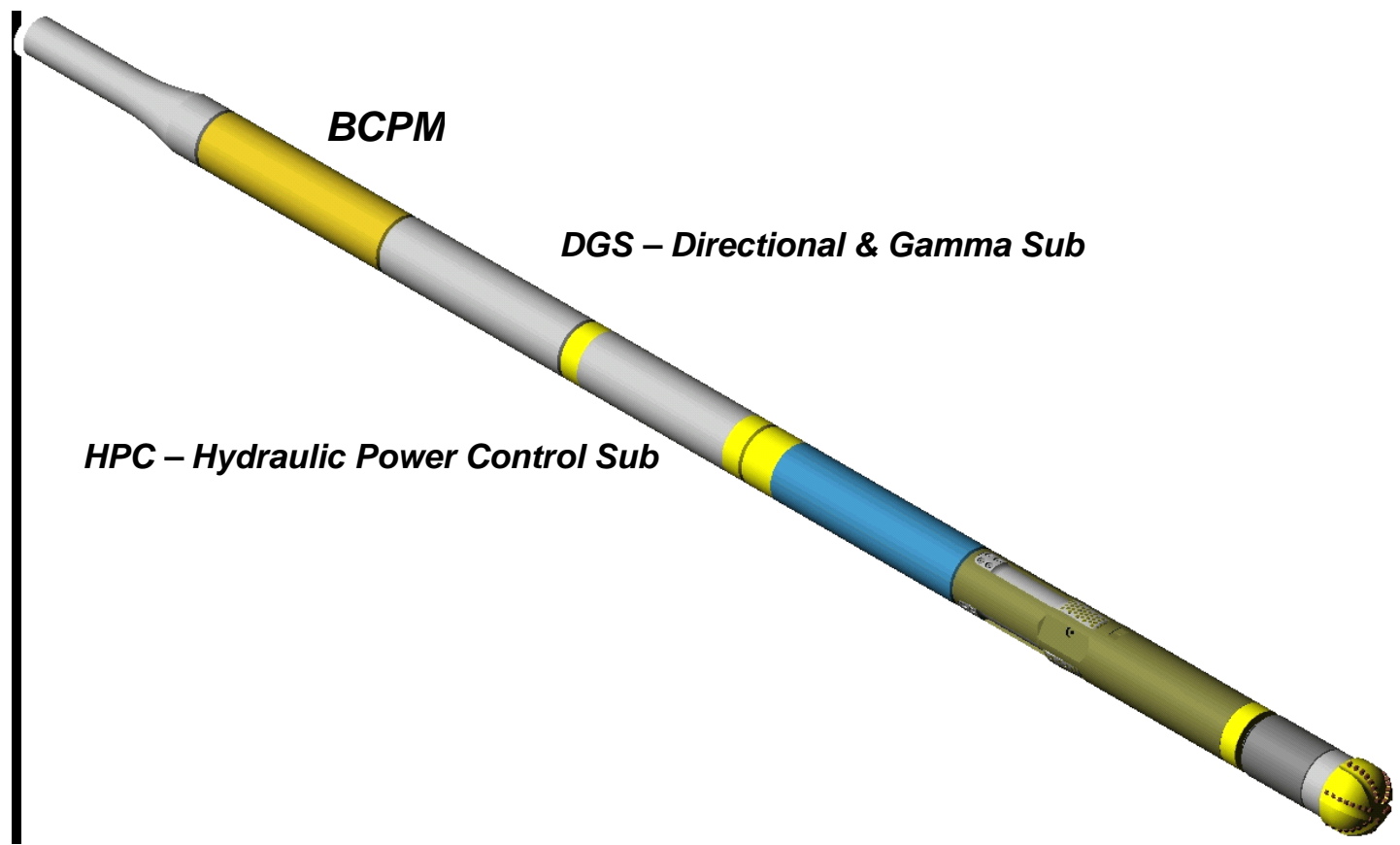

Figure 3: Lower 2 3/8” CoilTrak BHA with Bi-Directional Power and Communication Module (BCPM)

The new Bi-Directional Communication and Power Module will complement the other CoilTrak components that are already in existence.

It is important to realize that the BCPM component is the downhole end of a bidirectional communication system. There are additional surface components which are required to communicate with the BCPM. These components, which are shown in Figure 4, are as follows;

o A By-Pass Actuator (BPA) which telemeters commands from surface to downhole by diverting fluid flow at the surface in a specific sequence which is detected and decoded by changes in the downhole turbine rpm.

o A demodulator, termed the Safe-Area Remote Acquisition (SARA) unit, which processes the pressure pulses transmitted from downhole and removes unwanted noise.

o The Advantage surface MWD system, which decodes the pressure pulses from the downhole pulser into data words, and then stores that data to a database. This data can be distributed, for example, a drillers rig floor display.

o Using INTEQ’s RigLink software, real-time data can be transmitted to a remote location. 


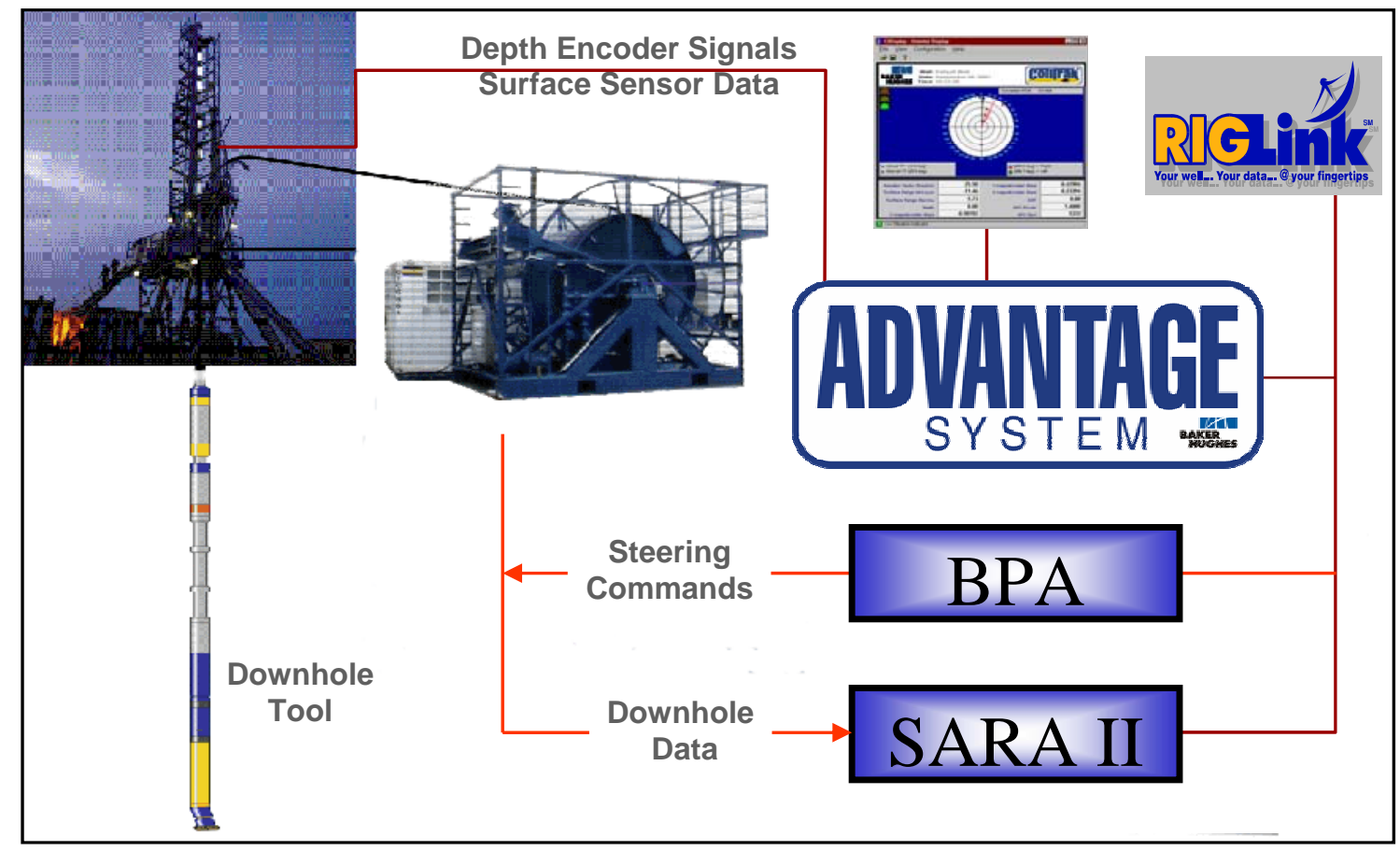

Figure 4: MWD Pulse Telemetry System Components for CT Drilling

\section{MWD Telemetry}

MWD telemetry is required to link downhole and surface MWD components in real-time, and ideally, should not interfere with drilling activity. The system to support MWD telemetry is quite complex, with both downhole and surface components that operate in tandem.

\section{Overview}

MWD Telemetry is the process of transmitting information between downhole MWD tools in the BHA, and surface computers. Up-Linking is the process of transmitting information from downhole to surface, and conversely, Down-Linking is the process of transmitting information and commands from surface to downhole. Connectivity between downhole and surface is described as half-duplex: information is transmitted in both directions, but not simultaneously.

In telemetry systems, a Telemetry Channel carries information. In MWD telemetry, there are several telemetry channels that can carry a signal, and these can be grouped into two classes: those that require no change

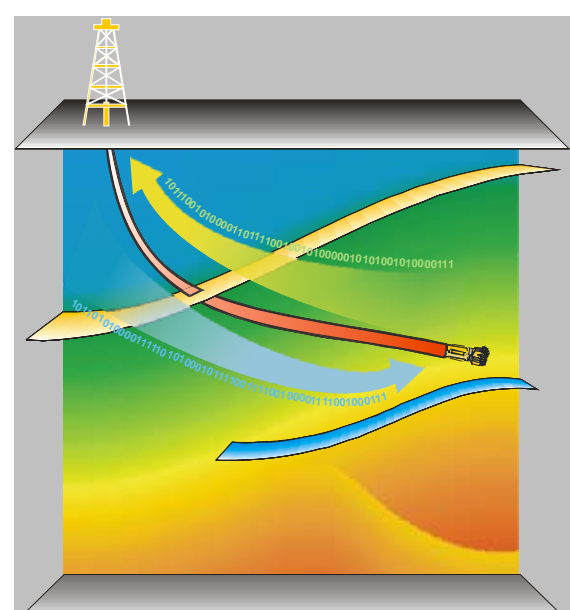

Figure 5: A basic MWD Telemetry system is a halfduplex system. 
to the drillstring, and those that require either a modification to the drillstring or a radical change in drilling practices. For simplicity, we can refer to the first as existing telemetry channels, and the second as additional telemetry channels.

\begin{tabular}{|c|c|c|c|}
\hline \multirow{9}{*}{$\begin{array}{l}\text { Table 1: Existing } \\
\text { and Additional } \\
\text { MWD } \\
\text { Telemetry } \\
\text { Channels and } \\
\text { Methods }\end{array}$} & & Channel & Example Telemetry \\
\hline & Existing & Drillstring Bore & Mud Pulse \\
\hline & & Drillstring Wall & Stress-Wave \\
\hline & & Annulus & - \\
\hline & & Formation & Electro-Magnetic \\
\hline & Additional & Wired-Pipe & IntelliPipe $^{\circledR}$ \\
\hline & & Cable & Coiled Tubing \\
\hline & & Fiber-Optic & - \\
\hline & Miscellaneous & Retrievable & - \\
\hline
\end{tabular}

Examples of Transmission Methods that transmit information in the telemetry channels include mud pulse telemetry (MPT) which uses the fluid filled bore of the drillstring; stress-wave telemetry (SWT) which transmits acoustic signals within the wall of the drillstring; electromagnetic telemetry (EM) which transmits a signal through the formation; wired-pipe telemetry (WPT) such as that employed by IntelliPipe ${ }^{\circledR}$, a technology developed as a DOE/NETL funded project by Novatek, Inc., and now operated by IntelliServ, which employs wired joints of oilfield tubulars; and finally E-line, the bi-directional communication employed by Coiled Tubing systems that utilizes a wire in the coil.

We can further classify the transmission methods based on how far they can transmit information, and their channel capacity, which is the amount of information they can potentially convey. The channel capacity is usually expressed in bits (binary digits) per second. The transmission methods, when classified in this manner, range from conventional methods which use existing channels and are limited in capacity, to those that are unconventional and use additional channels that can handle a greater flow of information.

A system that can only transmit information over a short distance can have its reach extended by using repeaters. The downside to the use of repeaters is added cost and complexity, and a potential decrease in reliability. However, if repeaters enable a high channel capacity then a multi-repeater system may be commercially

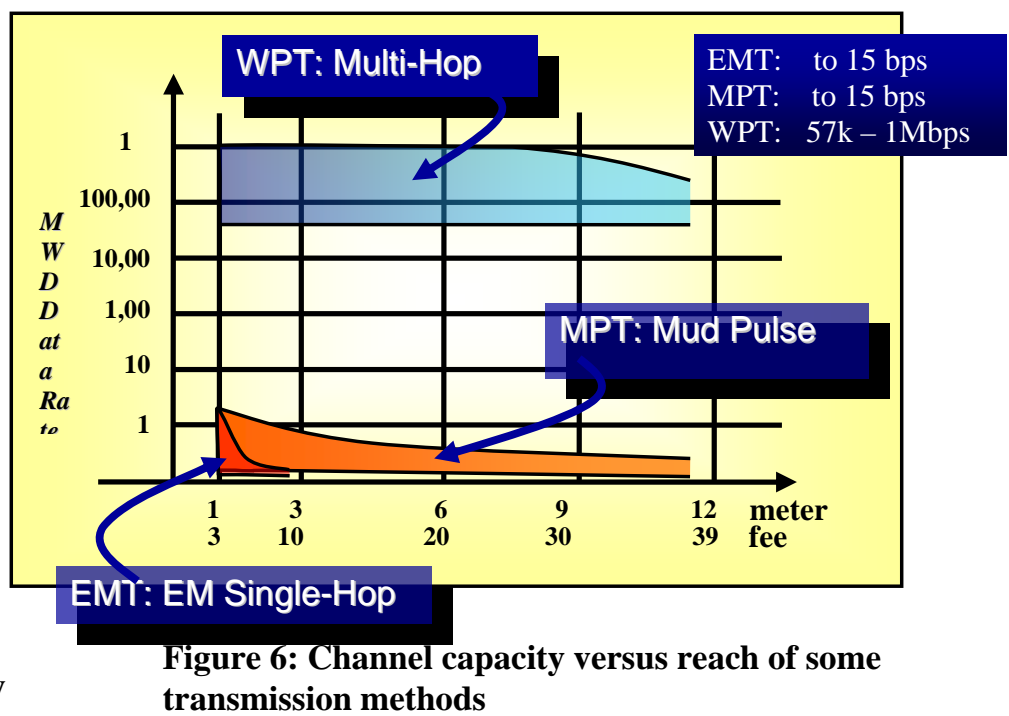

12 
viable. An example of a system employing multiple repeaters is wired pipe; the reach between each pair of repeaters is relatively short (200 to 500 meters), but the reach of an entire system can be $10 \mathrm{~km}$, or more.

From a technical standpoint, the ideal MWD telemetry system is one that has great reach and high potential data rate, such as a fiber-optic system. These systems, however, are intrusive to rig operations - handling the cable during drilling operations is not trivial and although money is being spent on developing these methods, they remain research topics. The methods used now in commercial drilling operations (methods whose cost makes them commercially viable) are Mud Pulse Telemetry and Electro-Magnetic Telemetry. Both of these are relatively low data rate systems, but the first offers great reach in mud-filled boreholes while the second, though of limited reach, has a niche market in air and under-balanced drilling applications and can be used in shallow wells that are filled with conventional drilling fluids.

In summary, MWD telemetry is the process of up-linking and down-linking information between the surface and downhole MWD tools. There are various methods of transmitting MWD information, and these can be classified in terms of the telemetry channel they use, the volume of information they can handle per unit time, the distance the information can be transmitted, and cost. Current commercial systems use either mud pulse telemetry, or electro-magnetic telemetry, to transmit relatively low rates of information over long or short distances, respectively.

\section{Mud Pulse Telemetry}

In any telemetry system, there is a transmitter and a receiver. In MWD Telemetry, the transmitter and receiver technologies are often different if information is being up-linked or down-linked. In up-linking, the transmitter is an MWD tool in the BHA (commonly referred to as the Mud-Pulser, or more simply the Pulser) that can generate pressure fluctuations in the mud stream, The surface receiver system consists of sensors that measure the pressure fluctuations, and signal processing modules that interpret these measurements (Figure 7). 


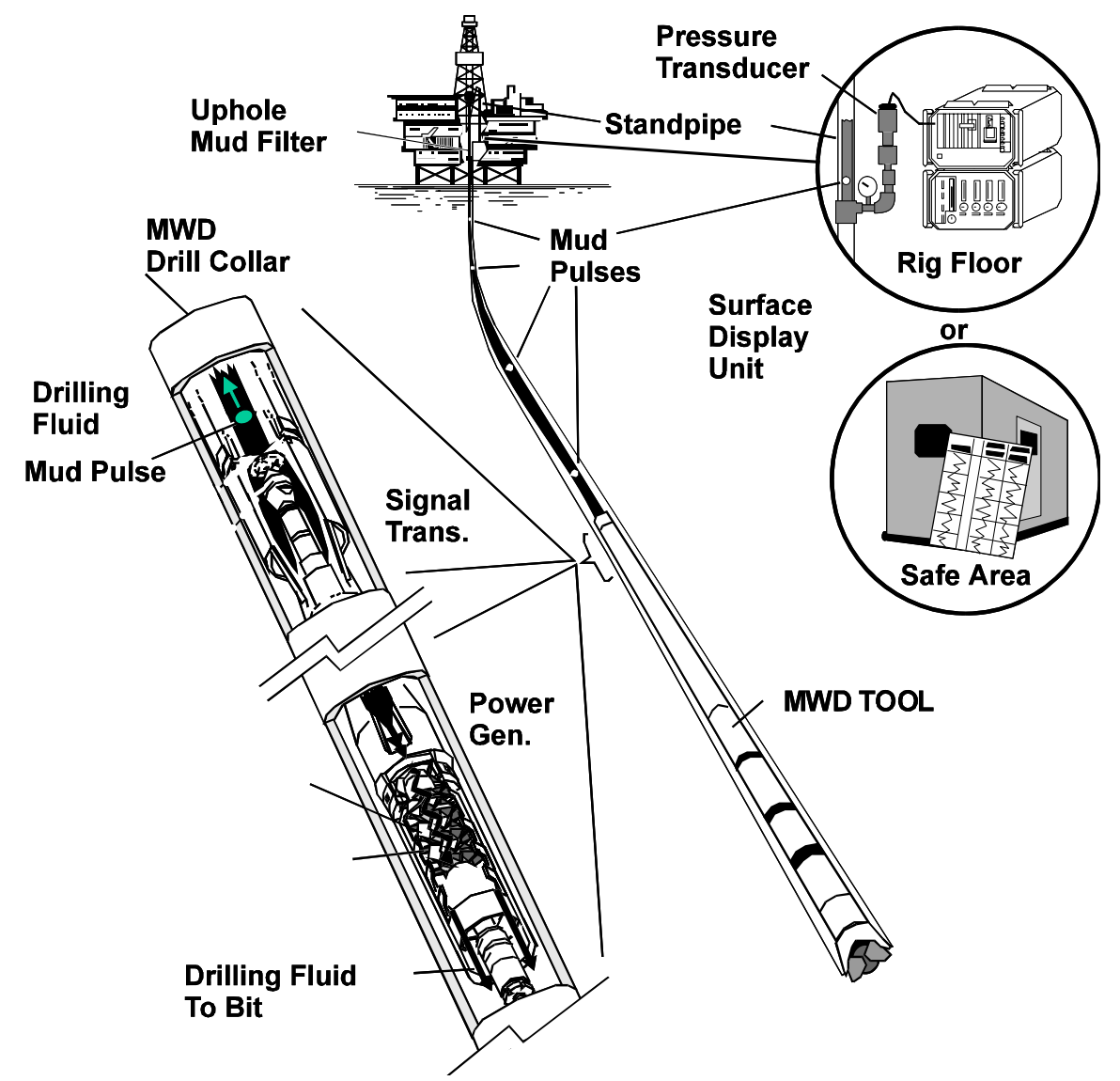

Figure 7: MWD tool communications to surface. The pulser is equivalent to the transmitter, the channel is the mud filled drillpipe and the receiver is the transducer mounted in the standpipe at the rig floor.

Down-linking may be achieved by periodically varying the flow-rate of the mud in the system or by periodically varying the rotation rate of the drillstring according to a timed sequence. To down-link using flow rate adjustments, as in the 2-3/8” BCPM, the flow rate is controlled on surface using a bypass-actuator and controller or by directly varying the output of the rigs mud pumps. Downhole in the MWD system, a sensor and electronics that respond to either flow or pressure changes detects the down-link signal.

MWD service companies employ their own commercial mud-pulsers to transmit the data from downhole to surface. There are currently several different types of pulsers in use, and we can classify them based on the type of signal they can generate: discrete pulses or continuous-wave signals. Discrete pulses can be either negative or positive, leading to the two classes of mud-pulsers that generate only discrete pulses: the negative and positive pulsers. Rotary valve pulsers can generate continuous-wave signals, while a relatively new class of pulser, the shear-valve pulser, is capable of generating both discrete and continuous-wave signals.

All mud pulsers operate independent from the surface. That is, there is no direct electrical or mechanical connection from the downhole tools to the surface. 


\section{Positive Pulse}

Pulsers that are "Positive Pulse" contain a mechanism that partially restricts the flow of drilling fluid inside the drill pipe. This restriction results in an increase in hydraulic pressure. Pulses transmitted in the mud inside the drill pipe propagate at the speed of sound in mud (between 900 to $1,450 \mathrm{~m} / \mathrm{s}$ ) to the surface, where they are sensed by a pressure transducer, measured and processed.

There are several pulser designs that fall into this category. The most common of which is the 'Poppet Valve' design.

Two variations of this type of pulser exist; one uses the pressure of the mud to assist opening the valve, in other words a "hydraulically assisted" valve.
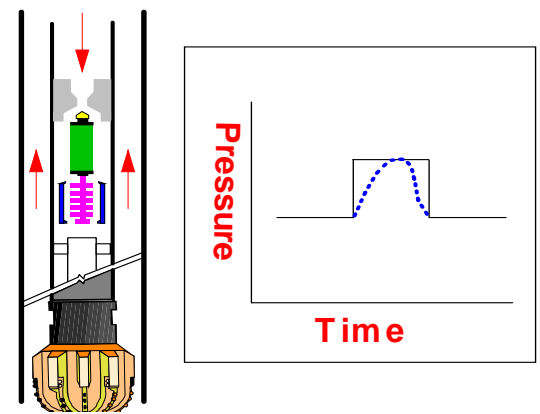

Figure 8: Positive pulse Pressure restriction inside the drillpipe, momentarily increase the pressure measured at the standpipe on the rig floor. These energy-efficient pulsers are capable of data rates up to about 12 bits per second; the 2-3/8” BCPM is of this type. The second type is fully isolated from the drilling fluid and consequently requires more power to open the valve. The advantage to the second type is that it in not prone to plugging by solids or Lost Circulation Material (LCM) in the drilling mud, which makes this type of design highly reliable. Telemetry rates may be significantly lower than 12 bps with this second type, because the higher data rates require higher power.

\section{Negative Pulse}

The Negative Pulse pulser uses a method (generally, a rotating valve) to vent some of the drilling fluid to the annulus. This results in a momentary pressure drop as seen at the standpipe on the rig floor. This type of pulser is not hydraulically assisted; as it is not operating in direct opposition to the flow of mud, this pulser does not require the same amount of power as a fully enclosed positive pulse pulser. It is power efficient and is capable of higher data rates. Additionally it is also less susceptible to plugging by solids or LCM because of the shearing action of the valve.

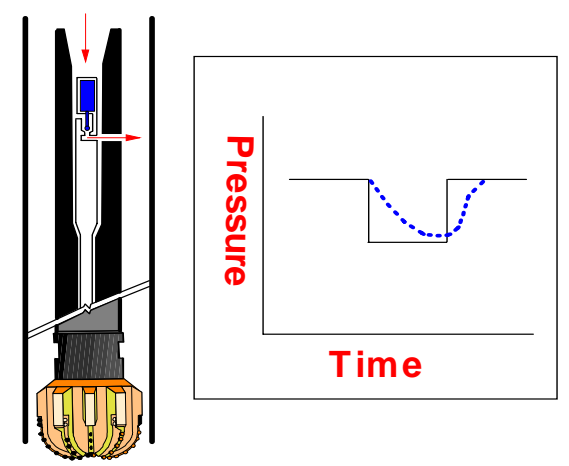

Figure 9: Negative Pulse Pressure restriction inside the drillpipe, momentarily decreases the pressure measured at the standpipe on the rig floor. 


\section{Rotary and Shear}

The pulsers described above are only capable of generating a train of discrete pulses, either negative or positive. Pulsers of the rotary or shear valve design can generate continuous wave signals at a given frequency, and the information is encoded either in the frequency of the signal, or its relative phase (this is explained in more detail in the next section).

These types of pulsers consist of two slotted disks, placed one above the other perpendicular to the mud flow. One of the disks is stationary (the stator) while the other is free to rotate (the rotor). The speed of the rotor controls the frequency of the continuous pressure wave generated in the mud. If the rotor moves in one direction then the valve is termed a rotary valve. If the rotor oscillates so that the aperture of the two disks is controlled, then the valve is termed a shear valve. Generally, rotary valves can generate only continuous-wave signals while shear valves are versatile and can generate both discrete and continuous wave signals.
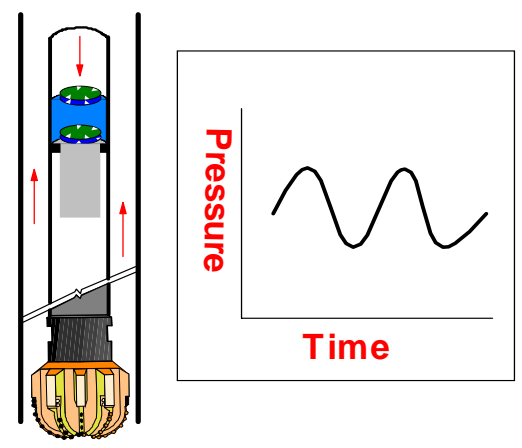

Figure 10: Rotary and shear valves. Pressure restriction inside the drill pipe created by a rotor within the pulser.

\section{Pulse Position Modulation (PPM)}

The Microhole Wireless Steering While Drilling System uses Pulse Position Modulation to encode information in the mud pulses generated by the 2-3/8" BCPM. In Pulse Position Modulation, the information is encoded in the position of a number of pulses within a specified time interval. The time line is divided into intervals of equal time, termed slots. This type of scheme is a word-based transmission system: a word of K-bits is encoded $M$-pulses, which can occur in $N$-slots.

The rules for creating the pulse pattern to represent a word are relatively straight-forward: a K-bit word is represented by $\mathrm{M}$ pulses in $\mathrm{N}$ slots.

Since there is not one pulse per bit, the calculation of the bit rate of a PPM code can be complex. However, the

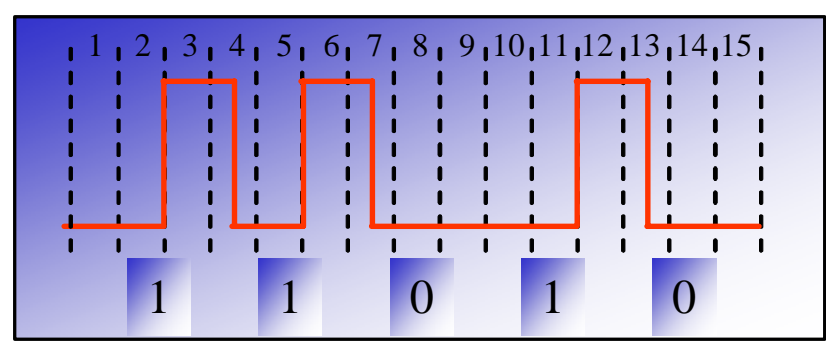
relationship between bit rate and pulse width can be generalized as:

Figure 11: PPM pulse pattern representing the 5-bit word '11010' 


$$
b p s=\approx \frac{5}{7 p w}
$$

Pulse Position Modulation is very efficient in terms of pulses per bit: it requires only 6pulses to transmit 16 bits. For comparison purposes, other modulation schemes will require between 11 to 21 pulses to transmit 16 bits of information.

There is one additional advantage to using PPM codes: they come with built-in error detection. The pulse pattern rules limit the possible locations of valid pulses, and can be used to discriminate between valid pulses and those created by noise sources.

\section{MWD Telemetry System}

Up to this point we have discussed the downhole transmitter and the way in which information is encoded in a sequence of pulses. To summarize: the digital signal from downhole - a sequence of 1's and 0's - is transmitted directly in the mud stream using pulse position modulation.

The downhole transmitter is, however, only one part of the MWD telemetry system. The other elements of the telemetry system are the transmission channel, surface receiver, and additional surface and downhole processing layers. The surface and downhole components of the system are designed to provide a reliable system delivering the highest possible bit rate.

The surface system is basically the inverse of the downhole system, with a few extra tasks added to compensate the measured signal for distortion during transmission.

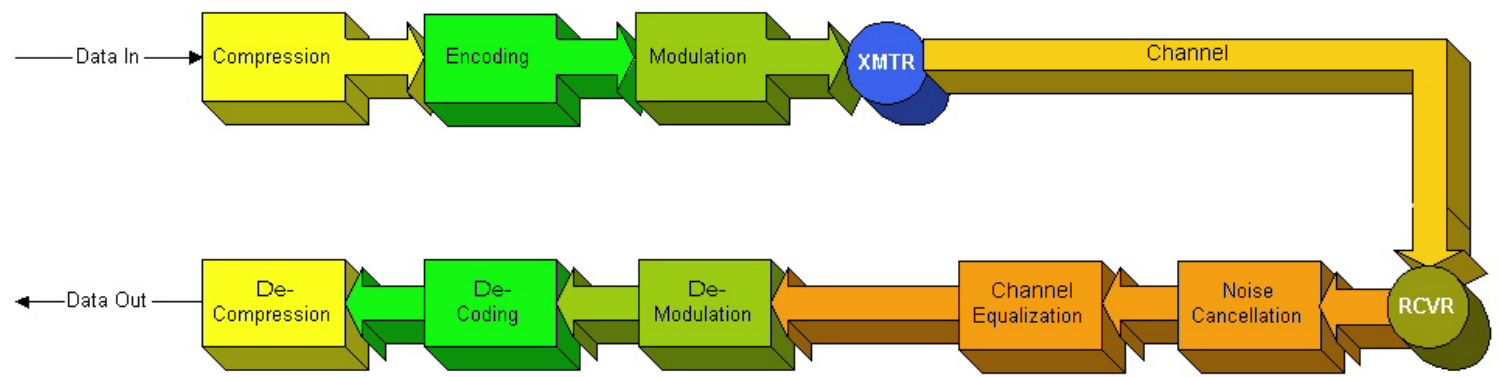

Figure 12: Block diagram of the MWD telemetry system, showing matching downhole and surface components.

In the downhole system the data is compressed and then formatted for transmission; error correction, if required, is added at this point by appending additional bits. It is then encoded and modulated. This is the final waveform delivered to the transmitter; with some synchronization overhead added at this point.

At the surface receiver system the signal, distorted during transmission and with various additive noise components, is measured by sensors whose number and complexity depends on the difficulty of transmission and the downhole tool being used. These signals are treated to remove the noise components and distortion, and the downhole transmission process reversed: the data are demodulated, and then synchronized and 
decoded; bit errors are detected and if possible, corrected; words are then parsed and decompressed, and delivered to their final destination, a database, where they are grabbed by other routines for permanent storage or transient calculations.

So far, we have described some of the encoding components used by the Microhole Wireless Steering While Drilling System that are in general use. Now we will look into the surface measurements, data acquisition systems, and surface processing in general.

\section{Signal Attenuation}

Successful MWD mud pulse decoding is dependent on a large range of interrelated variables, each of which adds to the decoding challenge and each of which can vary in importance with the configuration of the rig and borehole. Some of the variables are mud type and properties, drillstring hydraulics, surface pumping equipment type and condition, rig surface hydraulic configuration, pulse amplitude and shape, measured and true vertical depth, wellbore profile, drilling dynamics, and so on. It is fair to say that the drilling environment is dynamic and unique, and a challenge to achieving high data rate mud pulse telemetry.

One of the challenges that successful MWD decoding has to overcome is the marked attenuation of the MWD signal with depth. As the chart below shows, increasing depth has a significant influence on the amplitude of the signal measured at surface. For example, if the pulser strength is $200 \mathrm{psi}$ at the tool when the pulser is activated at 20,000 feet, then the received signal at surface in water based mud can be as small as $30 \mathrm{psi}$. Due to the compressional properties in oil based mud the signal on surface is even smaller, perhaps $10 \mathrm{psi}$ at this depth. Delivering adequate signal strength at the tool, so that it can be detected at surface, is an important mud pulser property.

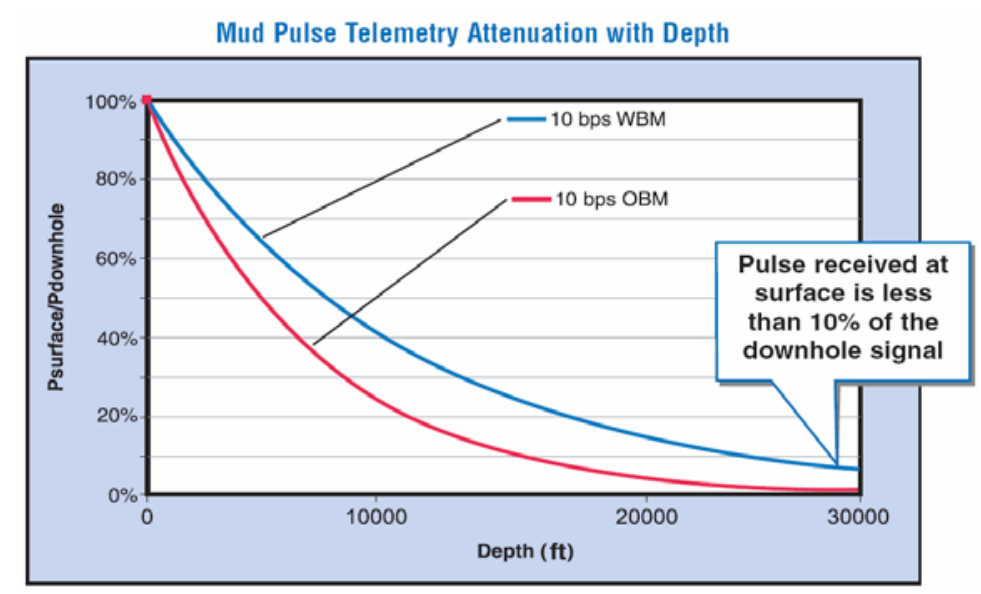

Figure 13: Pulse height as measured at the tool becomes severely attenuated with depth

Successful decoding at extended depths becomes a significant challenge with pulse height of 5 psi or less at depths beyond 30,000 feet. In order to mitigate this attenuation, to maintain an acceptable signal to noise ratio, MWD service companies reduce data rates to maintain decoding performance. At these depths, telemetry speeds are generally less of a factor in maintaining good measurement depth resolution, as penetration rates 
are normally substantially less than those reached in surface hole. In other words, although data rates are slower at depth, LWD data density can be maintained. While attenuation affects all telemetry schemes, some schemes may be more easily transmitted in this environment.

The ability to downlink to the MWD tool gives MWD service companies the ability to improve signal decoding by changing date rates, without tripping. Reducing data rate results in longer pulses, which improves the probability of pulse detection.

\section{Noise Sources - An Overview}

In MWD telemetry we use a very broad definition of noise: noise is anything other than the MWD telemetry signal in the measurements. Since the amplitude of the noise is often larger than the amplitude of the signal, we use several techniques - some simple, some not so simple - to remove noise and enhance the signal.

The ratio of signal power to noise power in the measurements is termed the Signal-toNoise Ratio (SNR), and is usually represented in decibels (dB). A value of 0 means that the signal and noise have the same power, while positive values mean that there is more signal power than noise power, and negative values the reverse - that there is more noise power than signal power. The objective of much of the noise cancellation is to increase the SNR in the measurements.

Noise is generally considered to be additive: a waveform is generated at the pulser and as it travels up to the measurement location several other signal components - occupying either a narrow or a wide frequency bandwidth - are added. The noise cancellation task is to ideally remove all of the added noise components in the measured signal. This is done with a collection of techniques, from simple "canned" filtering where the operator can

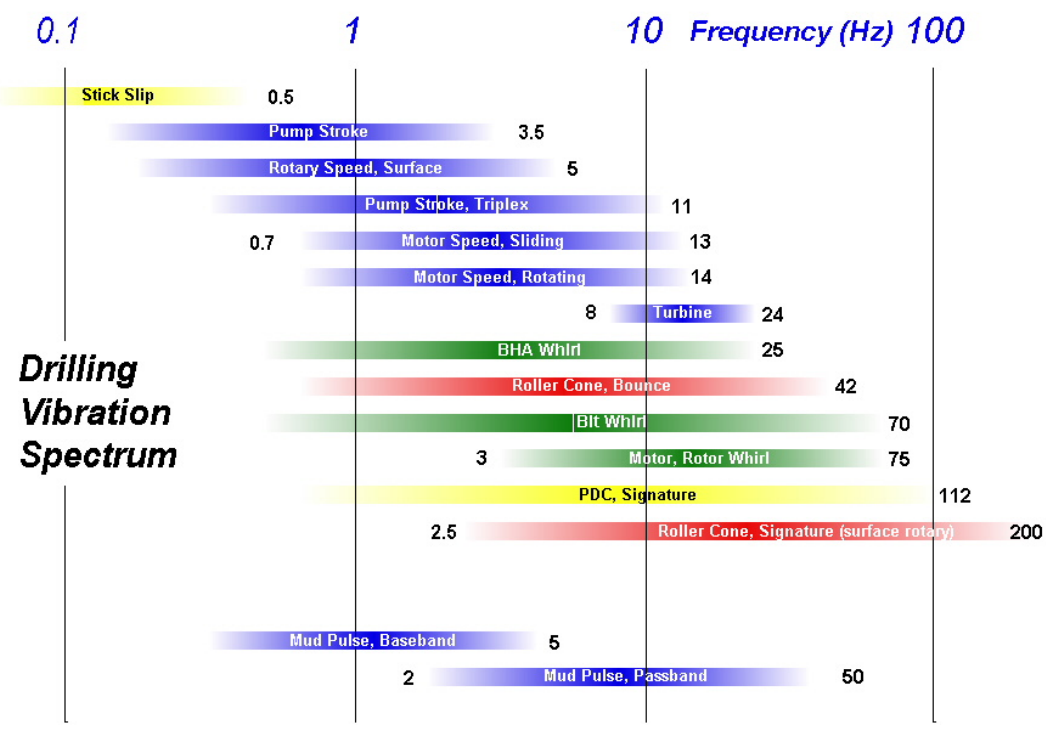

Figure 14: Drilling related noise sources, with their frequency ranges choose from a set of filters, through matched filtering where the received symbol is correlated with a desired symbol shape, to active filtering where independent measurements of the noise are made and removed from the measurements.

Drilling noise sources are summarized in the diagram in Figure 14, which shows the likely frequency range for each source. The frequency range for baseband mud pulse telemetry is from zero to about $5 \mathrm{~Hz}$, and for 
passband telemetry is from about 2 to $40 \mathrm{~Hz}$. For simplicity, noise sources can be grouped into pump sources, drilling excitation sources, and drilling dynamics sources.

\section{Summary}

The preceding text should have served to provide some idea of the complexity of MWD mud pulse transmission. Although it is one of the most difficult data transmission problems in any industry at the current time, MWD companies are able to successfully transmit data, in both directions, through the viscous drilling fluid.

Baker Hughes INTEQ, under cooperative agreement DE-FC26-05NT15488 with the U.S. Department of Energy, undertook to build a 2-3/8” device to transmit data by mud pulse for microhole drilling. The developed tool is described in the next section, followed by laboratory and field testing of the three prototypes. 


\section{Results and Discussions}

This section of the Final Technical Report simply describes the BCPM and BPA components in some detail, and describes the laboratory testing and field-testing that concluded the project.

\section{Bi-Directional Communication and Power Module}

Three bi-directional communication and power module's (BCPM) were prototyped. The object of the BCPM is to deliver power and communication services to the 2-3/8" CoilTrak BHA without the requirement for a wire inside the coil.

The BCPM provides system power and regulation; reception of commands transmitted from surface using flow changes; uplinking of data (downhole to surface) using mud pulse telemetry (MPT); and both real-time and conditional telemetry of data.

The dimensions and operating specifications for the BCPM are shown in the next table.

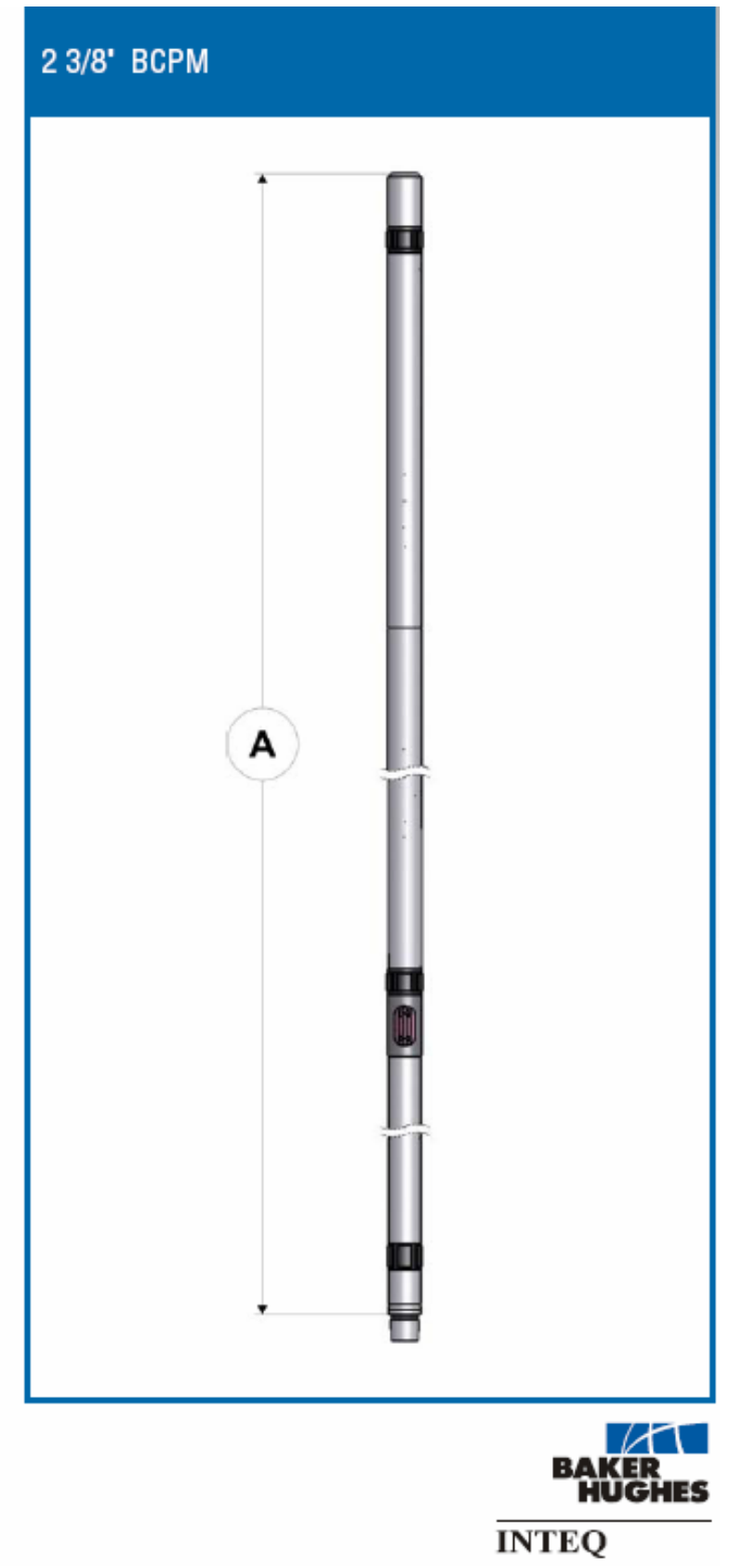




General Tool Specifications
\begin{tabular}{ll}
\hline Tool Size (OD) & $23 / 8^{\prime \prime}(60.3 \mathrm{~mm})$ \\
\hline Borehole Size Range & $3^{\prime \prime}-31 / 2^{\prime \prime}(76 \mathrm{~mm}-89 \mathrm{~mm})$ \\
\hline Length (A) & $16.7 \mathrm{ft}(5.1 \mathrm{~m})$ \\
\hline Weight & $165 \mathrm{lbs}(75 \mathrm{~kg})$ \\
\hline Tool Connection Top / Bottom & $11 / 2^{\prime \prime}$ AMT / 2 3/8" HDI \\
\hline Primary Power Source & Drilling Fluid driven Turbine \\
\hline
\end{tabular}

\begin{tabular}{|c|c|c|}
\hline Operational Data & & \\
\hline Wear Sleeve & \multicolumn{2}{|c|}{$2.62^{\prime \prime}(66.5 \mathrm{~mm})$} \\
\hline Flow Rate & \multicolumn{2}{|c|}{$\begin{array}{l}45 \mathrm{gpm}-80 \mathrm{gpm} \text { (170 lpm - } 300 \mathrm{lpm}) \\
\left.{ }^{*}\right) \text { - min. flow rate for Downlink Operation }\end{array}$} \\
\hline Maximum WOB & \multicolumn{2}{|c|}{$8,800 \mathrm{lbf}(39 \mathrm{kN})$} \\
\hline Maximum Overpull to failure & \multicolumn{2}{|c|}{$8,800 \mathrm{lbf}(39 \mathrm{kN})$} \\
\hline Maximum Tensile Load & \multicolumn{2}{|c|}{$64,300 \mathrm{lbf}(286 \mathrm{kN})$} \\
\hline $\begin{array}{l}\text { Temperature Range } \\
\text { Operating } \\
\text { Survival }\end{array}$ & $\begin{array}{l}\text { Maximum: } \\
300^{\circ} \mathrm{F}\left(150^{\circ} \mathrm{C}\right) \\
347^{\circ} \mathrm{F}\left(175^{\circ} \mathrm{C}\right)\end{array}$ & $\begin{array}{l}\text { Minimum: } \\
-4^{\circ} \mathrm{F}\left(-20^{\circ} \mathrm{C}\right) \\
-40^{\circ} \mathrm{F}\left(-40^{\circ} \mathrm{C}\right)\end{array}$ \\
\hline Min Diagnostic \& Tool Assembly Temperature & \multicolumn{2}{|l|}{$39^{\circ} \mathrm{F}\left(4^{\circ} \mathrm{C}\right)$} \\
\hline Maximum Hydrostatic Pressure & \multicolumn{2}{|c|}{20,000 psi (1,379 bar) } \\
\hline Sand Content & \multicolumn{2}{|c|}{$\begin{array}{l}1 \% \text { max. Volume, acc. to API 13B (<0.5\% } \\
\text { recommended) }\end{array}$} \\
\hline Maximum LCM & \multicolumn{2}{|c|}{ TBD } \\
\hline Maximum Axial \& Lateral Vibration & \multicolumn{2}{|c|}{$\begin{array}{l}5 \mathrm{~g} \text { RMS ( } 1-250 \mathrm{~Hz} \text {; } 1 \text { sec integration) or } \\
\text { equivalently } 45 \mathrm{~g} \text { peak ( } 0.025 \mathrm{sec} \text { shock pulse } \\
\text { duration) (from recorded memory or as flagged } \\
\text { by real-time severity level) }\end{array}$} \\
\hline
\end{tabular}

The BCPM is comprised of three main components: the pulser, the alternator and the electronic control unit.

\section{Pulser}

The pulser consist of a Main Valve Assembly (MVA) and a Control Valve Assembly (CVA). During operation, drilling fluid flowing through the coil tubing ID hits the pulser and diverges. In the open valve state, not actuated, a portion of the fluid passes through 
the gap in the MVA valve and restrictor. The remainder of the fluid travels into the inlet screen and down through the center of the MVA guide. The fluid that goes through the center of the MVA fills up underneath the MVA valve before exiting through the bottom MVA guide into the CVA. Once in the CVA, the fluid travels over a poppet valve that is normally open and then exits through holes in the CVA housing. This is the point where both fluid paths merge back together.

When the CVA is energized, the CVA poppet valve extends forward restricting the flow of fluid through the MVA guide. This in turn builds up pressure underneath the MVA valve which causes it to extend forward and restrict the flow of fluid past the restrictor. This restriction causes a pressure wave which travels to the surface as a pressure pulse.

\section{Alternator}

The alternator has two main purposes. One is to power the tool and the other is to provide turbine speed for downlinking. The alternator has a multistage turbine which is driven by the mud flow. The turbines are connected to a magnetic shaft which rotates within the ID of a windings package. The rotating shaft generates an energy field which outputs through the windings as 3-phase AC power. Power output is directly related to turbine speed. For downlinking purposes, the turbine speed along with specified timing intervals is used to send codes downhole to the electronics.

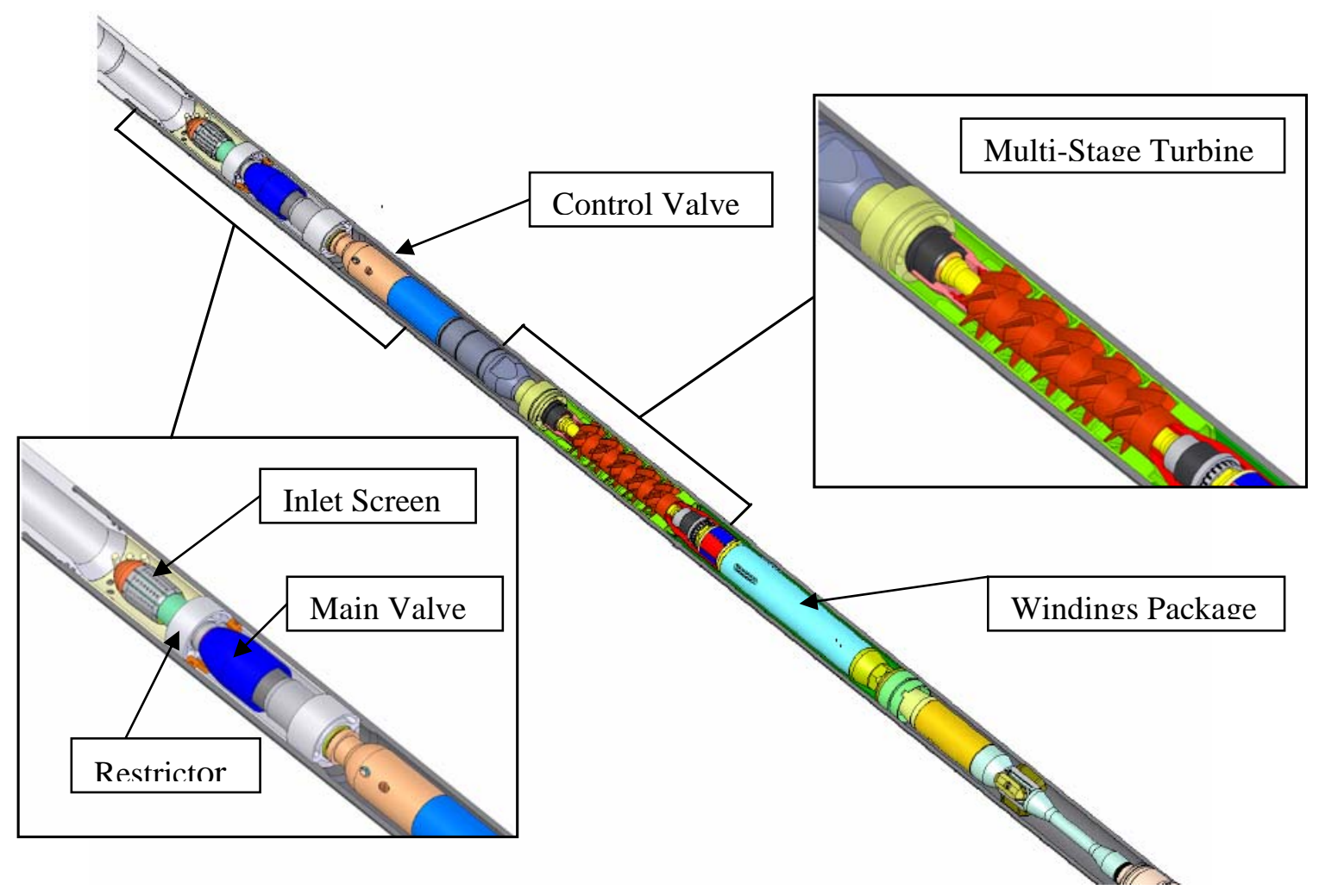

Figure 15: 2-3/8" BCPM Components 


\section{Electronics Control Unit (ECU)}

The ECU performs 3 main functions: Power Regulation, Bi-Directional Communication Control and Pulser Control

Power Regulation - The 3-phase AC voltage from the alternator is converted to DC and is then regulated to a constant voltage for use by all MWD electronics. The ECU has upper and lower thresholds which only allow power output when then alternator turbine rpm is within the specified operating range.

Bi-Directional Communication Control - The ECU constantly monitors turbine rpm and through a sequence of varied flow rates, controlled at the surface using the bypass actuator, can interpret changes in turbine rpm and decode as downlink commands. These downlink commands can be used to reconfigure the tool downhole.

Pulser Control - Data is gathered, encoded, and then transmitted to the surface via pressure pulses generated by actuating the CVA in a specified sequence.

\section{Bypass Actuator}

The Bypass Actuator (BPA) is used to communicate commands from surface to the MWD/LWD tool string in the BHA. This system is called "Downlinking" and a wide range of different commands can be communicated to the BHA. These include precise steering settings for the Rib-Steering Motor (RSM), modification of MWD telemetry, and manipulation of various LWD sensor functions. With the wide range of commands available, the downhole systems are able to drill more precisely, provide the most appropriate real time data at all times, and can stay in hole without tripping to be reprogrammed.

The BPA is part of the surface system which allows Downlinking. It was designed and built to operate in all hole sizes - but for the 2-3/8” Coil Tubing system, it was necessary to modify the BPA to work with the low flow rates and pressures available.

The BPA is connected directly to the rig mud circulation system at any point between the pumps and the standpipe with a second low pressure connection to the mud return line. It is powered by rig supplied compressed air and controlled remotely from the MWD cabin. Communication to the BHA is achieved via negative pulse telemetry controlled remotely from the MWD cabin. When a Downlink is required, the BPA automatically transmits the signal by diverting a portion of the mud flow away from the standpipe in pulses to the return line. This sequence of negative pulses is decoded by the downhole assembly and 
the associated changes are made within the BHA. A typical Downlink takes about 4 minutes, and can under ideal conditions be performed on bottom while drilling ahead.

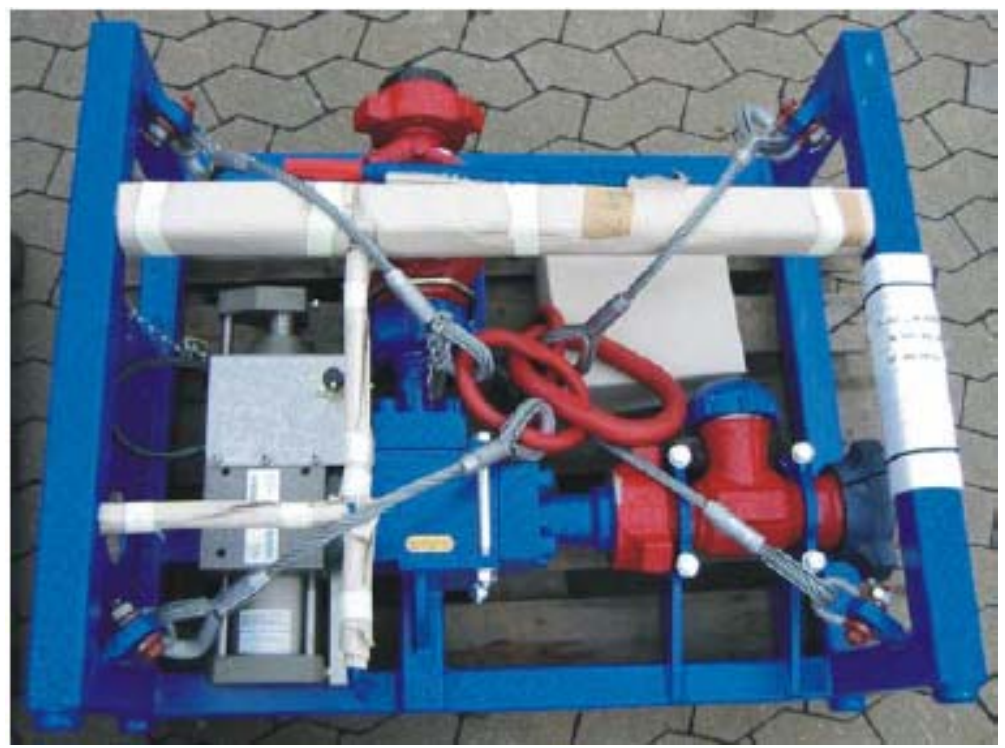

Figure 16: Bypass Actuator 


\section{Laboratory and Preliminary Integration Testing, 2-3/8" BCPM}

Laboratory and flow loop testing of the 2-3/8” BCPM was complex since the BCPM had to be tested alone, and then with other CoilTrak components. Laboratory and Integration testing was performed in the Baker Hughes Technology Centers in Houston, Texas, and in Celle, Germany. The formal test schedule is shown in the next table.

\begin{tabular}{|l|l|l|l|}
\hline Formal Test Type & Period & \multicolumn{2}{|c|}{ Location } \\
\hline Primary Test & April 16-20, 2007 & Celle & Flow Loop \\
\hline Integration Test, CTK BHA & May 7-11, 2007 & Celle & Flow Loop \\
\hline Downlink/Decoding Test & June 14-21, 2007 & Celle & Flow Loop \\
\hline Transmission Protocol Test & July 17-20, 2007 & Celle & Laboratory \\
\hline Integration Test with MPR & Sep 10-25, 2007 & Houston & Flow Loop \\
\hline Integration Test, RSM, MPR & Nov 7-12, 2007 & Houston & Flow Loop \\
\hline Field Trial & Nov 14-21, 2007 & Oklahoma & BETA \\
\hline Coil Test & Dec 4-6, 2007 & Houston & Flow Loop \\
\hline
\end{tabular}

This section of the report describes the tests through the final integration tests with the RSM and MPR components, in November of 2007. The next section will discuss the results from the field trial and the final test with a coil.

Primary Test, April 16-20, 2007

Objective: Decoding and Downlink Test of the 2-3/8” BCPM

Result: $\quad$ Successful

\section{Discussion}

The 2-3/8” BCPM was tested in the flow loop with the DPS (Drilling Performance Sub), DGS (Directional Gamma Sub) and HOT (Hydraulic Orientor) components of the CoilTrak BHA. The objective was to confirm correct functioning of the uplink decoding system (the BCPM correctly encodes the data and the BCPM pulser unit works to specification), and the downlinking system (the Bypass Actuator correctly encodes the information, and the BCPM properly interprets the received pulses).

The test was successful, as indicated in the summary below.

\begin{tabular}{|l|l|l|}
\hline Test & Comments & Result \\
\hline Decoding Test & Direct decoding, 2 bps & Successful \\
\hline Downlink to change data rate & Change to 0.7 bps & $100 \%$ \\
\hline Downlink to change data rate & Change to 1.5 bps & $100 \%$ \\
\hline Downlink to change data rate & Change to 2.0 bps & $98 \%$ \\
\hline
\end{tabular}




\begin{tabular}{|l|l|l|}
\hline Downlink to change data rate & Change to 1.5 bps & $100 \%$ \\
\hline Downlink Testing & & Successful \\
\hline Downlink to flow-off measurement & & Successful \\
\hline Downlink for Ribs-Off & & Successful \\
\hline Downlink for Steer Direction & & Successful \\
\hline Downlink to Change Telemetry & & Successful \\
\hline Downlink to Steer Dirn 1.5deg & confirmation failed & Successful \\
\hline Downlink to Steer Dirn 180 deg & & Successful \\
\hline Downlink to Steer Dirn 358.5 deg & & Successful \\
\hline Downlink to Steer Dirn 270 deg & & Successful \\
\hline
\end{tabular}

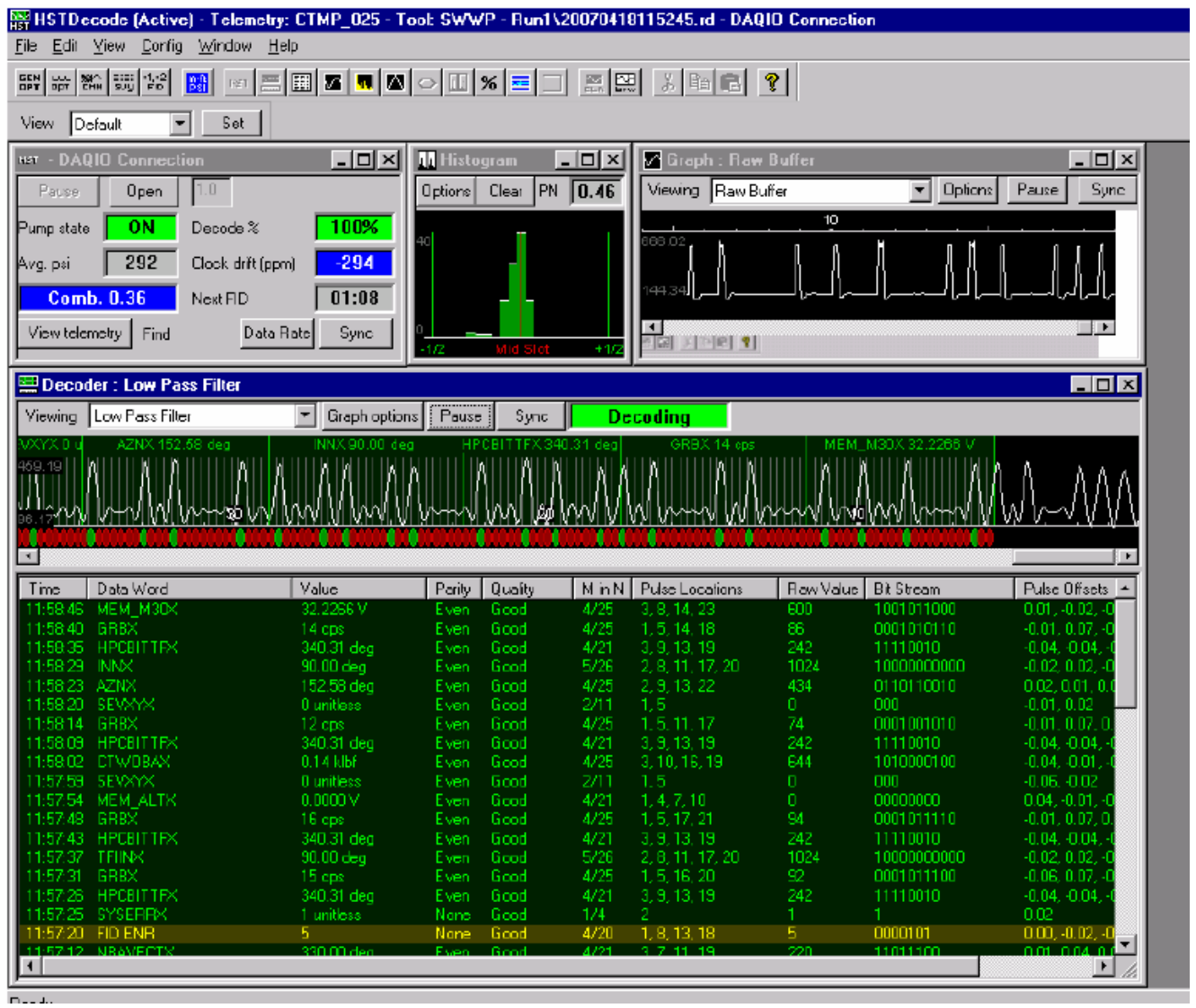

Figure 17: Example decoding screenshot taken during the initial decoding test. The raw signal is shown in the upper left black trace, while the extracted pulse is shown in the trace spanning the width of the plot, above the red bar which shows the location of the pulses. The lower text pane shows the decoded words which in this case are all good (green). Data rate is 2 bps. 


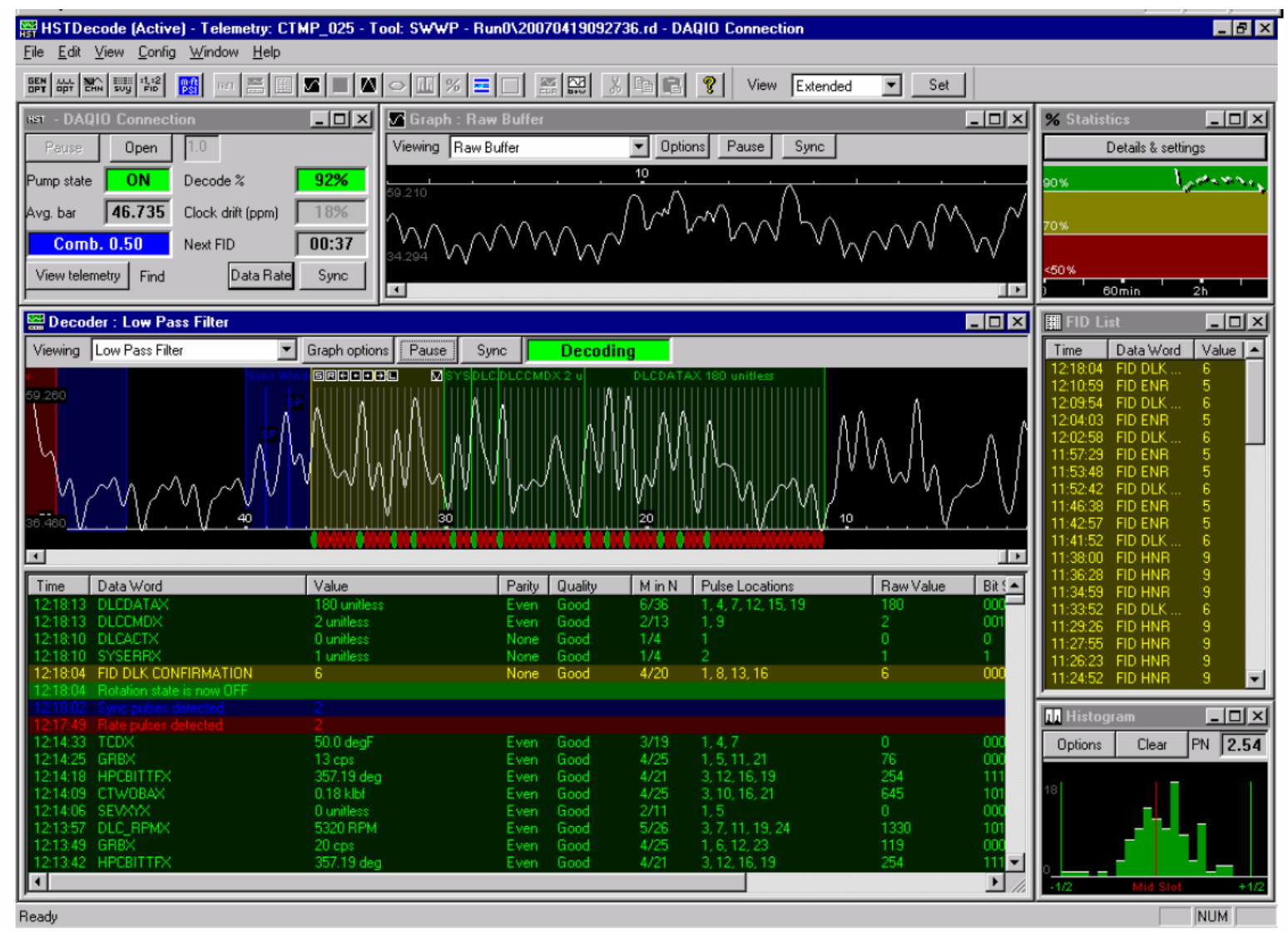

Figure 18: Screenshot of the decoding during the last test in which the Orienter was turned to 270 degrees. Flow rate was $270 \mathrm{l} / \mathrm{min}$, data rate was $1.5 \mathrm{bps}$. The downlink confirmation (successful) is shown as the yellow text in the lower pane.

Integration Test, May 7-11, 2007

Objective: CoilTrak BHA Integration Test the 2-3/8” BCPM

Result: $\quad$ Successful

\section{Discussion}

The 2-3/8” BCPM was tested in the flow loop with the DPS (Drilling Performance Sub), DGS (Directional Gamma Sub) and HOT (Hydraulic Orientor) components of the CoilTrak BHA. This was a full functional test with the following objectives:

- $\quad$ Check if the BCPM works with existing CTK modules (DGS, DPS, HOT)

- Check communication and data handling between modules

- Check the downlink functionality of the BCPM

- Check flow rates and range for downlinks 
- Check functionality of all modules with the Advantage surface system

The results are summarized:

- BCPM worked with CTK modules, powered both by a remote source (used to supply power on surface) and by the BCPM alternator.

- Communication and data handling between modules worked, issues were seen with WOB and Pressure sensor values, which might not be collected or calculated right in the Tool or in the Advantage software.

- CTWOB is not saved in the tool memory.

- Downlink functionality of the BCPM worked, all downlinks detected correctly

- Flow ranges tested from $170 \mathrm{l} / \mathrm{min}$ to $300 \mathrm{l} / \mathrm{min}$; downlink test range was the same. Data rate of 3 bps tested successfully at $270 \mathrm{l} / \mathrm{min}$.

- Functionality of the surface Advantage system tested, minor changes need to be done. This includes upgrading the Drilling Performance data words to use the surface taring function.

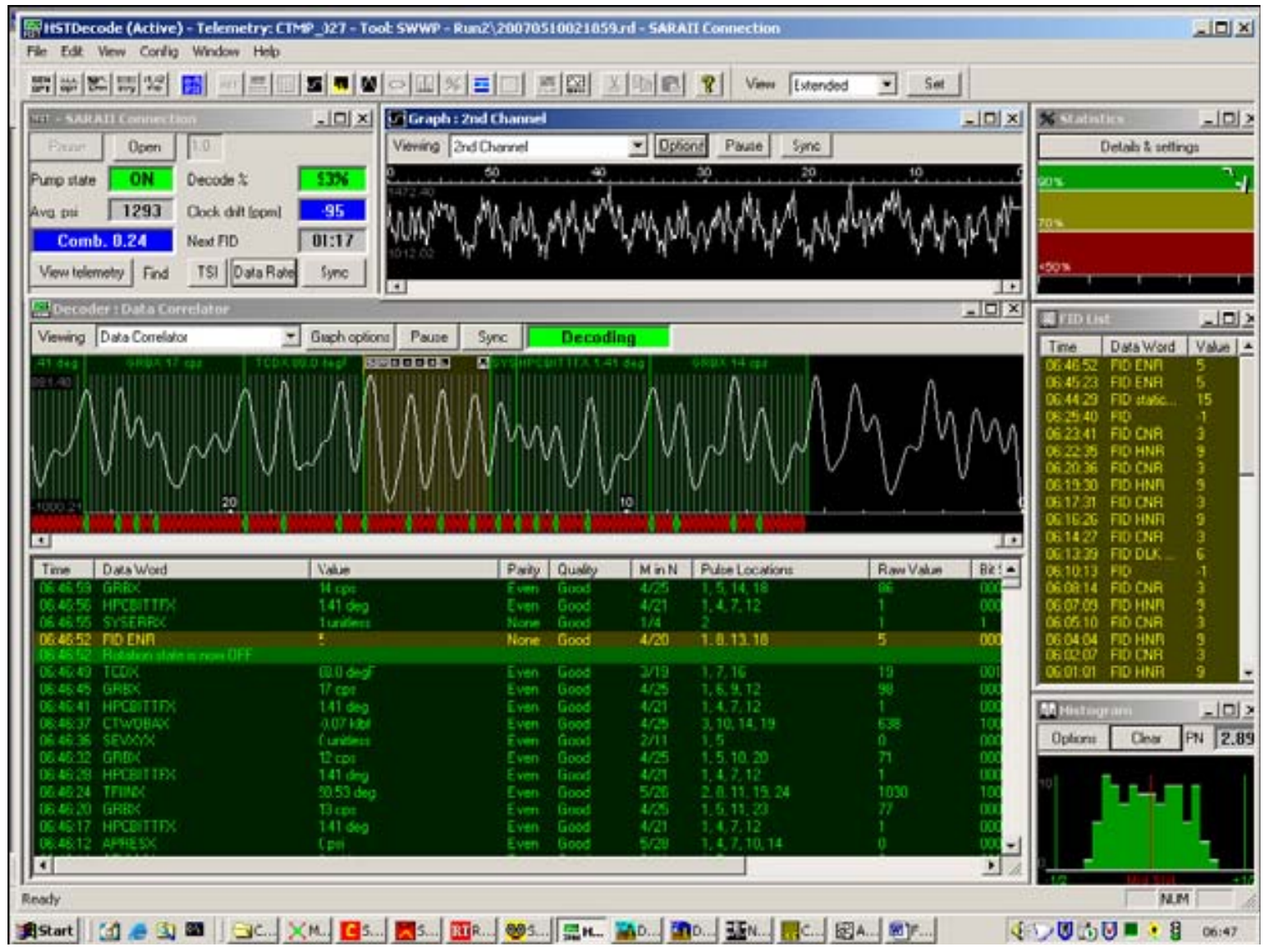

Figure 19: $100 \%$ decoding at 3 bps while flowing at $270 \mathrm{l} / \mathrm{min}$ in the flow loop. 
Objective: $\quad$ Test upgraded firmware for the 2-3/8” BCPM

Result: $\quad$ Successful

\section{Discussion}

The objective was to repeat the primary test parameters with a new cut of BCPM firmware. The results are shown in the table:

\begin{tabular}{|l|l|l|}
\hline Test & Comments & Result \\
\hline Decoding Test, 180 1/min & Decoding at 2 bps & Successful \\
\hline Downlink, data rate, 270 l/min & Change to 3.0 bps & $100 \%$ \\
\hline Downlink, data rate, 270 l/min & Change to 4.0 bps & $100 \%$ \\
\hline Downlink Testing & & Successful \\
\hline Downlink for Steer Mode & & Successful \\
\hline Downlink for Ribs-Off & & Successful \\
\hline Downlink for Steer Direction & & Successful \\
\hline Downlink to Steer Dirn 1.5deg & & Successful \\
\hline Downlink to Steer Dirn 357 deg & & Successful \\
\hline Downlink to Steer Dirn 180 deg & & Successful \\
\hline Downlink for flow-off measurement & & Successful \\
\hline
\end{tabular}

The uplink data rate during the test was maintained at 4 bps. An example screenshot is given below. 


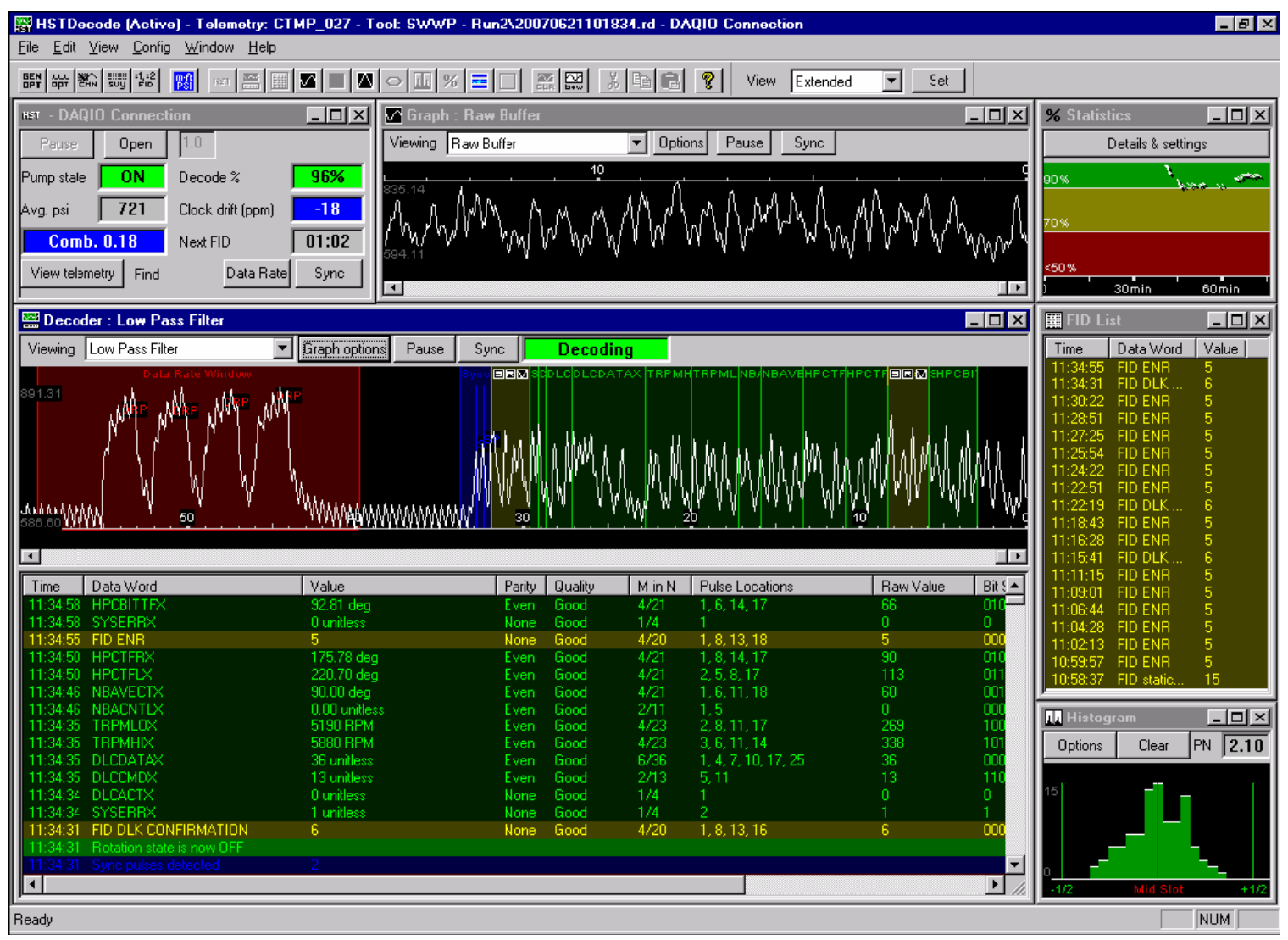

Figure 20: 100\% decoding at 4 bps, flow rate of 270 l/min.

\section{Transmission Protocol Test, July 17-20, 2007}

Objective: Test processing of the DSP words Result: $\quad$ Successful

\section{Discussion}

During the flow loop integration test of May 7-11, 2007, certain words (weighton-bit and pressure) were not handled correctly. This lab test was performed to ensure that this had been fixed. Results:

- The weight-on-bit data was successfully written to the BCPM Memory, and this was confirmed after memory dump

- The telemetry change of the tare function worked correctly and the tare correction can be processed in real-time 


\section{CTK BHA Integration Test, Sep 10-25, 2007}

Objective: Consolidation Test of CTK BHA components with the BCPM Result: $\quad$ Successful

\section{Discussion}

This was the first integration test held in Houston, and the objective was mainly to confirm the performance of the BCPM with other CTK modules in the Houston flow loop, and as a functional test for other changes made in the lab. New components added to the BHA at this stage were the MPR (Multiple propagation Resistivity) and the EDC (Electrical Disconnect Module)

- Check if the BCPM is working with other CTK components (HOT, DGS, DPS, EDC also MPR)

- Check communication and data handling

- Check downlink functionality of the BCPM

- Check start up and shut off flow rate

- Check if WOBM is written to BCPM memory, (dump memory)

- Check if changed DPS words (weight-on-bit) can be processed in Advantage and can be tarred

- Check the other transmitted words if they are still working correct, since the changes to the WOB word

\section{Results}

- BCPM worked with the new configuration and the other modules, powered both via a remote system, and via flow (alternator)

- Data handling and downlink functionality worked, all downlinks detected and confirmed

- EDC downlink could not be tested as circulation is required to downlink. This is detrimental to the seals of the EDC. Due to this reason, the EDC is not recommended to be part of a CoilTrak string with the BCPM.

- Start up and shut off flow rate successfully resolved (45gpm - 85gpm). Downlinks were sent over this operating range.

- The weight-on-bit was successfully stored in the BCPM Memory, confirmed after memory dump

- The telemetry changes to the tare function of WOB were fully functional and can be performed in Advantage. It was also confirmed from the tare history that the tare offsets were accepted and the changes applied successfully.

- All transmitted words were sent accurately and were confirmed by comparison between the words transmitted in real-time and the values stored and dumped from the BCPM memory. 


\section{CTK BHA Integration Test with RSM, Nov 7-12, 2007}

Objective: To test the BHA as it will be run at the BETA test site: BCPM with DGS (directional gamma sub), DPS (Drilling Performance Sub), MPR (Multiple Propagation Resistivity) and RSM (Rib Steering Motor)

Result: $\quad$ Successful

\section{Discussion}

- Check if the BCPM is working with the RSM

- Check if the RSM can be integrated in the CoilTrak mud pulse BHA

- Check communication and data handling

- Check downlink functionality of the BCPM

\section{Results}

- Integration of RSM in the CoilTrak mud pulse BHA was successful

- All components worked ok

- All RSM modes were check and tested ok

- Internal communication worked without error 


\section{Field Testing}

Project requirements were to field test the 2-3/8” BCPM in a commercial well in North America. However, after failing to locate an opportunity with any major oil company during a 6-month period, it was decided to execute a drilling test of the coil tubing BHA at Baker Hughes' test facility. This would permit a drilling test with other DOE funded components in the BHA - the Rib Steering Motor and Multiple-Propagation resistivity tools developed as part of NT-15407. Drawbacks with this test were that a coil tubing rig was not available, and the test involved running the BHA on the end of jointed tubing. This limited borehole cleaning, and the development of good pressure pulses.

Field testing of the 2-3/8” BCPM took place at the Baker Hughes Experimental test Area (BETA) near Beggs, Oklahoma during the period 14 to 21 November, 2007.

\section{Baker Hughes Experimental Test Area}

The Baker Hughes Experimental test Area is located approximately 20 miles South of Tulsa, Oklahoma. The purpose of the facility is to expedite the development and commercialization of drilling systems for the oil and gas industry.

\section{Background}

The Baker Hughes Experimental Test Area (BETA) provides a major bridge between small scale simulator and laboratory testing, and full scale field applications of downhole tools. Testing at BETA allows systems to be evaluated without the costs and constraints associated with a well being drilled for production.

BETA is located on a 640 acre lease (1 square mile) about 20 miles South and West of Tulsa, Oklahoma and about 33 miles from the Tulsa airport. The physical location is 1-1/2 miles west of highway 75 at 241st South in Beggs, OK. The facility has been in operation since in March of 1997, and has drilled in

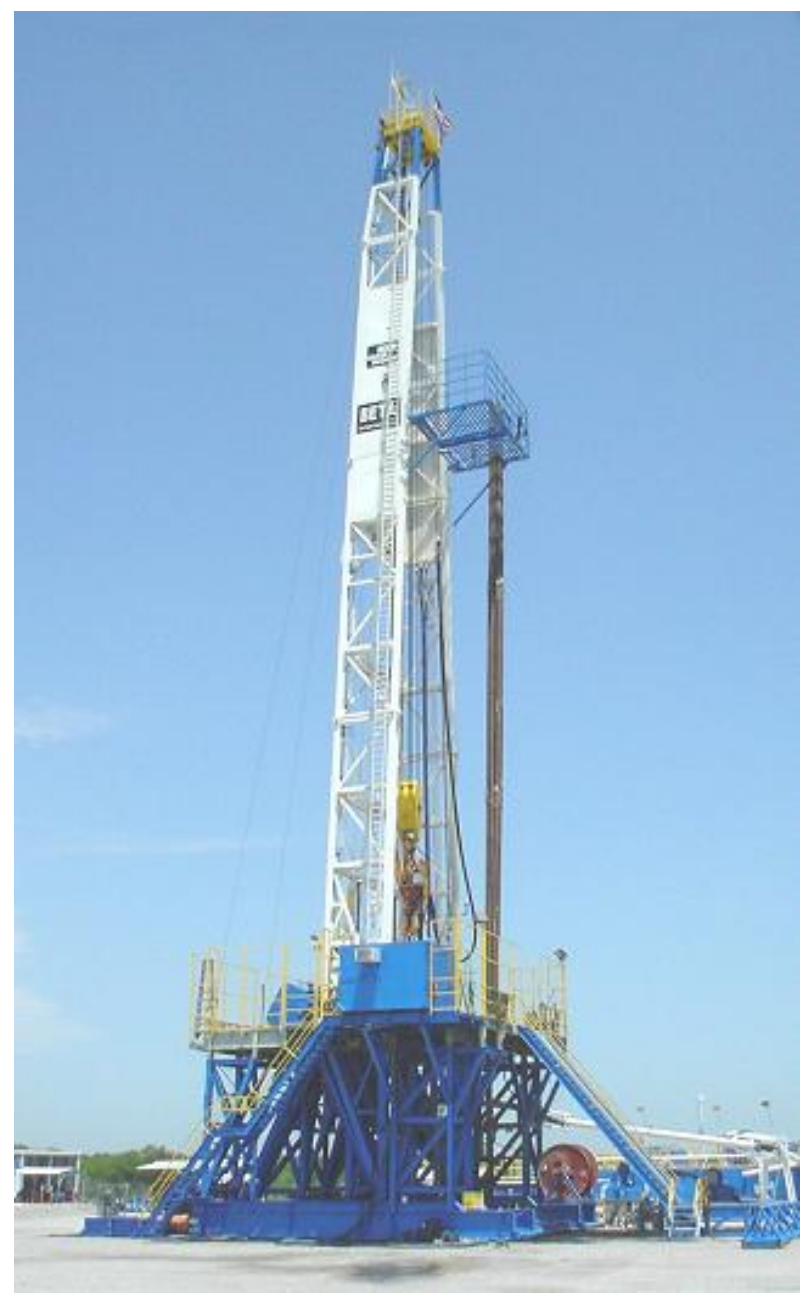

Figure 21: Baker Hughes Experimental Test Area (BETA) 


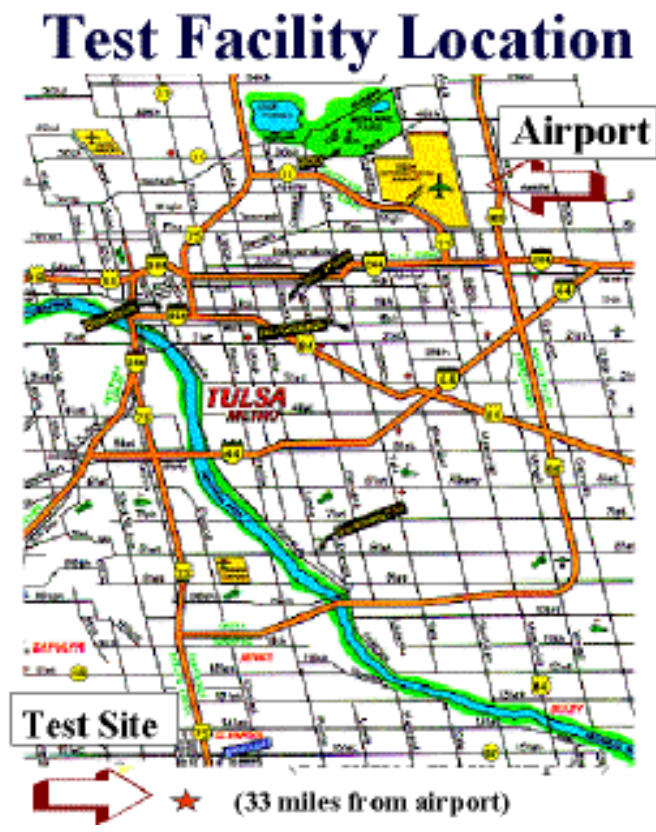

excess of 250,000 feet in 109 wells. The Figure shows the location of the facility.

The geology in and around the Tulsa, Oklahoma area is quite unique in that it offers a wide array of formation types within a relatively shallow depth. The geology at the new test site consists of a Pennsylvanian section from surface to 2,250 ft; a Mississippian section from 2,250 2,660 ft; and an Ordovician section from 2,660 down to the granite base. These formations include sandstone, limestone, shale, coal, dolomite, and granite. Many of the formations still contain residual amounts of oil and gas. In fact, much of the oil industry's early growth centered around Tulsa after the discovery of oil at nearby sites such as Redfork, Glenpool, and Barnsdall.

The presence of oil, gas, coals, permeable sands, and unstable shales provides conditions that closely mimic oil field conditions. The large variation in rock strength provides ideal test conditions for testing downhole tools and systems. The entire section between surface and basement has been cored and extensively logged. Petrophysical descriptions (permeability, porosity, compressive strength, etc.) of each formation were made available after the first well drilled at the facility, through the use of continuous wireline coring technology to retrieve the actual rock.

\section{Test Objectives}

The primary test objectives for the field trial of the BCPM were:

- Drill about 100 to $250 \mathrm{ft}$ of formation

- Prove the functionality of the $23 / 8$ ” BCPM with CoilTrak Mud Pulse Telemetry:

o Start-up/Drop-out flow rate (note: since the RSM component is limited to a range of 45 to 75 gpm, the upper limit of the BCPM - 85 gpm - would need to be tested with a mud motor)

o Decodable Pulse Height (with varying data rates)

o Pressure drops

o Down link capability

- Gain circulating and drilling hours on the tools

- Validate that the base CoilTrak Mud Pulse BHA performs correctly:

o DPS, DGS,HPC, HOT 
- Validate functionality of the transmitted words and downlinks

The secondary test objectives were to evaluate the performance of the RSM and the integration of the RSM in a Mud Pulse BHA.

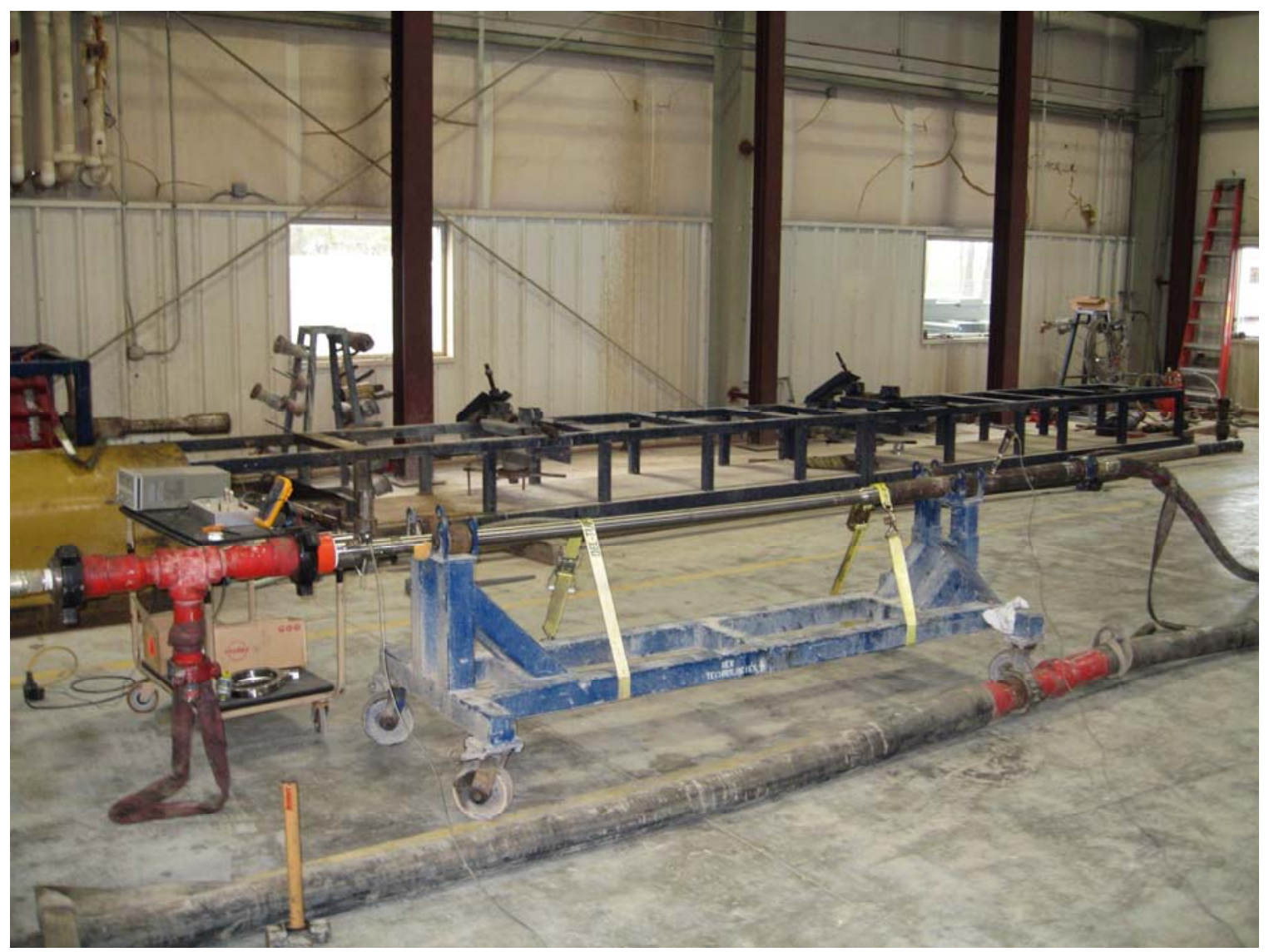

Figure 22: 2-3/8" BCPM operating in the Houston Flow Loop 


\section{Well Plan}

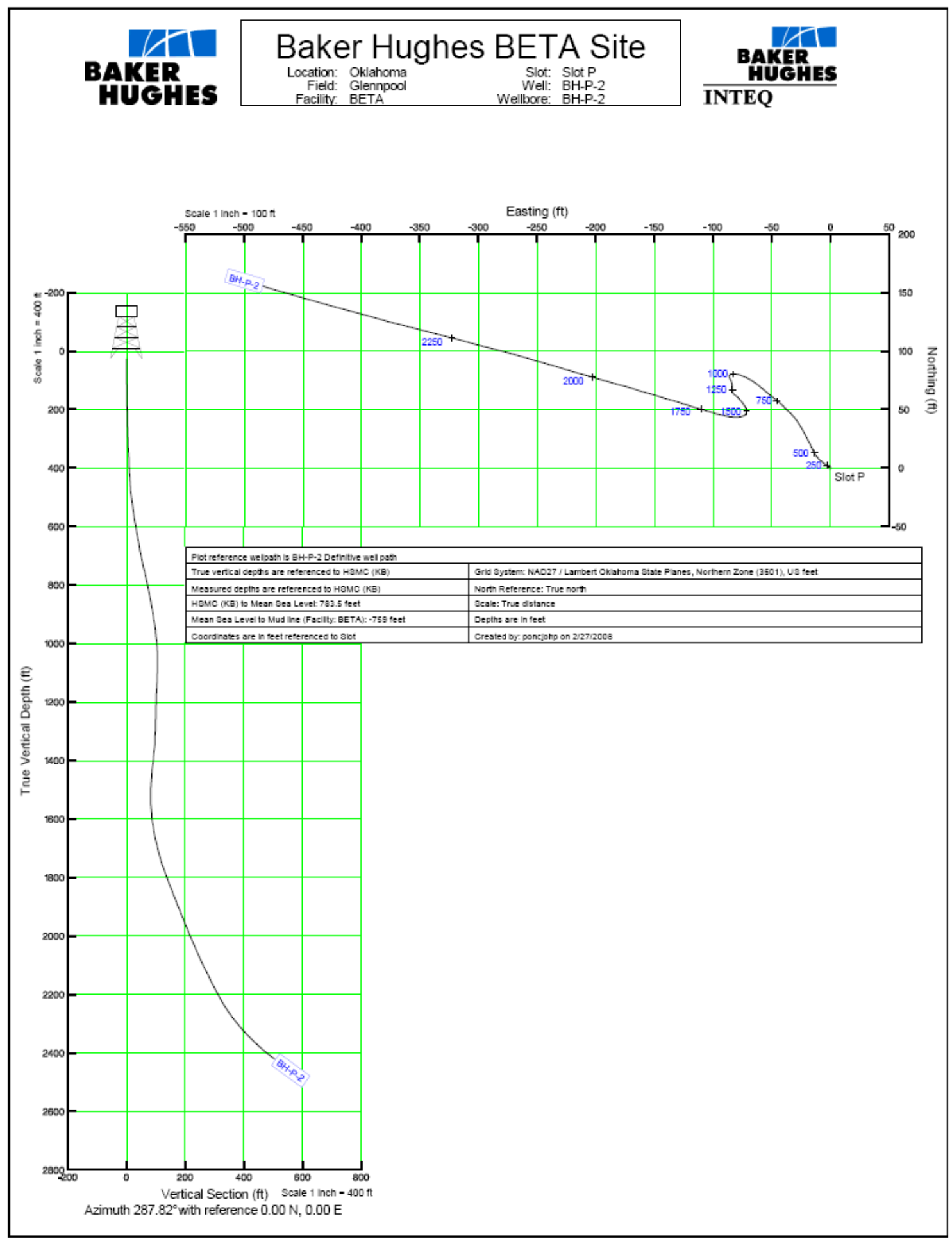


The well plan is shown in the overlying figure. Prior to the BCPM field test, a 6-1/8"hole was drilled to a measured depth of 2,613 feet with a final inclination of 55 degrees. The CoilTrak BHA with the BCPM, RSM and MPR drilled a 3" hole size from the base of the 6-1/8” hole. The pipe tally with BHA configuration is shown in the table below.

\begin{tabular}{|r|r|r|r|r|}
\hline Component & $\begin{array}{c}\text { Length } \\
\text { (feet) }\end{array}$ & $\begin{array}{c}\text { Cumm. } \\
\text { Length }\end{array}$ & $\begin{array}{c}\text { OD } \\
\text { (ins) }\end{array}$ & $\begin{array}{c}\text { ID } \\
\text { (ins) }\end{array}$ \\
\hline Bit & 0.59 & & 3.000 & \\
\hline RSM & 16.64 & 17.23 & 2.63 & \\
\hline MPR & 9.60 & 26.83 & 2.50 & \\
\hline DGS & 9.39 & 36.22 & 2.38 & \\
\hline DPS & 6.43 & 42.65 & 2.38 & \\
\hline Disconnect & 16.62 & 59.27 & 2.50 & \\
\hline Tubing & 244.34 & 60.85 & 2.13 & \\
\hline XO & 1.33 & 305.19 & 1.90 & \\
\hline 3 1/2 WP & 818.45 & 1124.97 & 3.50 & 2.25 \\
\hline 3 1/2 DP & 1488.73 & 2613.70 & 3.50 & 2.76 \\
\hline
\end{tabular}

The use of 3-1/2” tubing in a 6-1/8” existing wellbore represented a significant hole cleaning challenge. It was decided to proceed in 100 foot increments - should cuttings build up in the 6-1/8” hole section prove a problem due to the low flow rates (about 65 gpm), then a reaming run would be made to both clean the hole and open it to 6-1/8."

\section{Field Test Results}

\section{Run 1: Nov 15, 2007, 2613.7 feet, Failure To Transmit}

While the tool was successfully surface and shallow depth tested, the pulse height at 900 feet MD was 3 to 5 psi. When compared to the pulse height during the flow loop test (70 to 120psi) it is significantly smaller. At 2,100 feet, no pulses were visible and no decoding was possible. The decision was made to pull out of hole and change out the BCPM.

Before changing out the failed BCPM with a new one, it was tested again on the surface. The BCPM was powering the BHA (alternator working), but the pulser was not working. After removing the BCPM from the BHA, the Control Valve Assembly (CVA) of the pulser was energized and actuation could be heard. The decision was made to ship the unit back to Houston for evaluation. 


\section{Run 2: Nov 16, 2007, 2613.7 feet, Failure To Transmit}

A second BCPM was installed in the BHA and successfully tested at surface. At $700 \mathrm{ft}$ the tool did not pulse. Several attempts to revive the BCPM proved unsuccessful and subsequently it was pulled out of hole. Before removing the BCPM from the BHA at surface, it was connected with the Kelly hose directly on top of the BCPM to see if anything impeded the pulse signal from coming up. The bit was also removed and still the BCPM failed to pulse. It was then changed out with the third BCPM. As with the $1^{\text {st }}$ BCPM, the CVA valve of the pulser was energized and actuation could be heard. The memory was dumped from both failed BCPMs indicated that data was written into the memory which indicated that the main valve could have been stuck. The third (and final) BCPM was built into the BHA.

\section{Run 3: Nov 19 - 22, 2007, 2613.7 feet, drilled 141 feet.}

With the third BCPM, surface and the shallow transmission tests were both successful. The pulse height was around 20 to 30 psi. However, the pulse height was not as high as expected or seen in the flow loop. Prior to setting the bit on bottom the $61 / 8$ ” open hole section previously drilled was re-logged using the 23/8” MPR.

After reaching bottom, drilling was performed for about 100 feet until a downlink was transmitted to change steering parameters. After this downlink, the BCPM stopped pulsing. It started again after working the pipe and several back flushing attempts. It continued working for the next 41 feet until the BCPM failed again. Decoding was only possible at $45-85 \%$ due to insufficient pulse height. The data rate was 0.7 to 1.2 bps and the flow rate was approximately 65gpm.

The RSM test objectives were limited due to the short distance drilled. The plan was to drill for 100 feet to build angle and then downlink to change the settings. The RSM performed well during this test. The first 100 feet was drilled with 50\% steer force and the following 41 feet the steer force was increased to $75 \%$ to observe a difference. $100 \%$ steer force was not possible due to the limitation in the current output by the alternator in the 2-3/8” BCPM.

The BCPM and the RSM accumulated 13.6 drilling hours and drilled 141 feet of formation. After the test the 2-3/8” BCPMs were sent back to Houston for investigation and the 2-3/8” RSMs were shipped to Celle for maintenance.

\section{Post Field Test Analysis}

Post field test analysis focused on two issues (a) the failure to transmit in the first two runs and (b) the reason for the poor decoding on the final run. The first of these was 
rather easy to solve - the main valve of the pulsers in runs 2 and 3 were blocked with scale and debris. It is likely that this came from the tubing, which was rented.

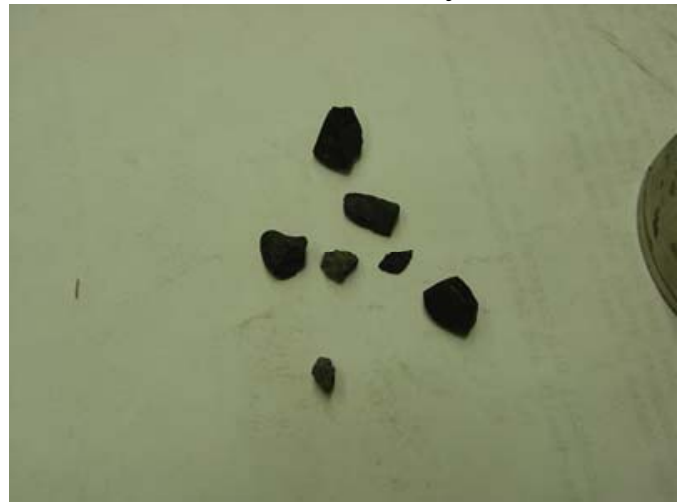

Figure 23: Debris extracted from inside the first BCPM during inspection in Houston, after the field trial at BETA

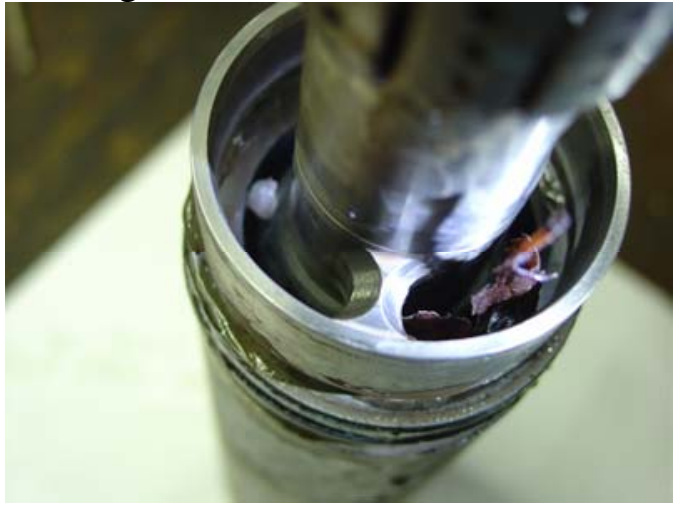

Figure 24: Debris (pipe scale) lodged within the BCPM. Disassembly after the BETA field trial.

The second issue, the poor decoding, was addressed by modeling mud pulse transmission through the hydraulic configuration at BETA. As can be seen in the pipe tally given earlier in the description, there were several significant changes in internal diameter within the drillstring alone. The modeled signal is shown in the first figure below, while the measured signal at the wellsite is shown in the second figure.

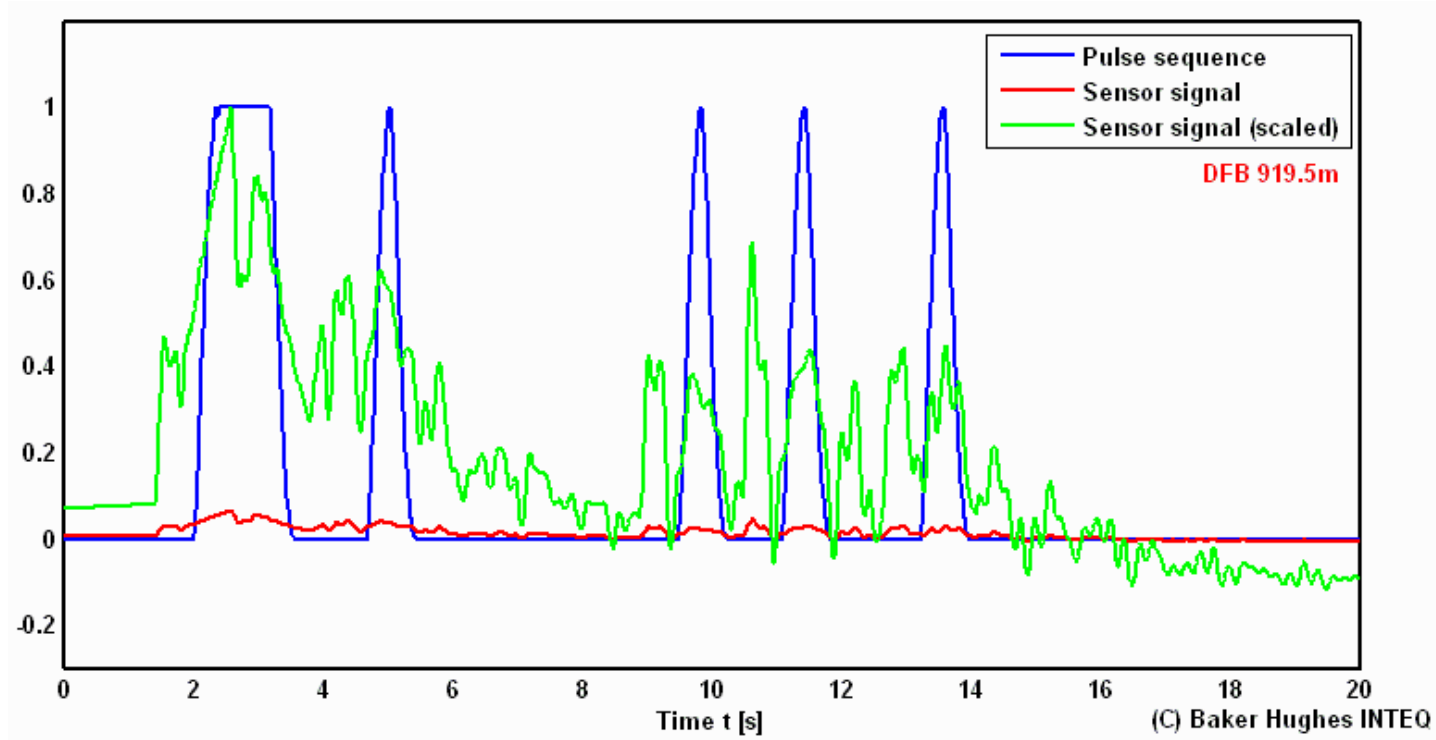

Figure 25: Signal simulation for BETA 2-3/8" BCPM test showing an initial pulse sequence (blue) and the modeled highly distorted surface signal (green) 


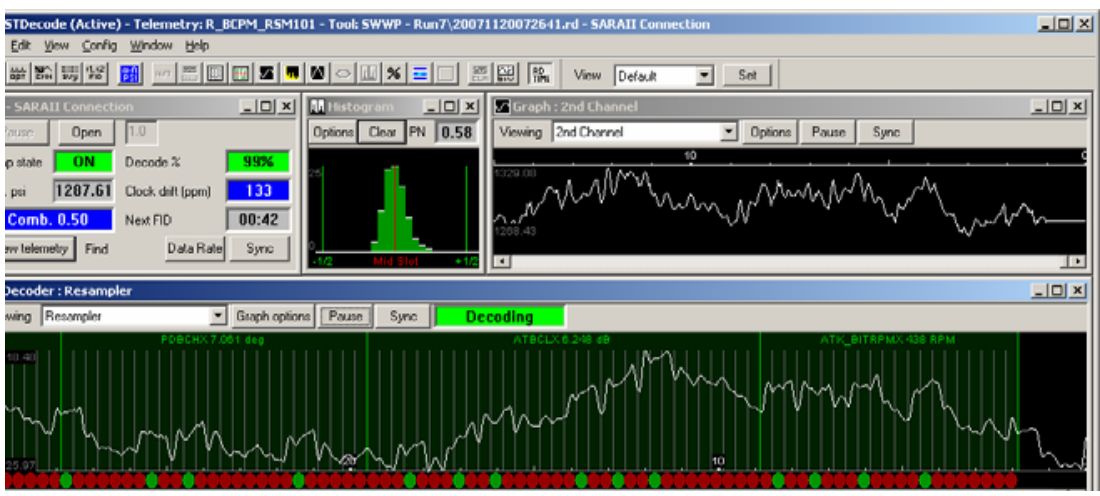

Figure 26: Measured and decoded signal, 2-3/8" BCPM field trial. Compare with the highly distorted signal predicted by simulation software in figure 25 .

The performance of the decoding achieved on run 3 at the wellsite was extremely good, given the high level of distortion due to the drillstring configuration. This non-standard drillstring configuration was needed to run the coil-tubing BHA with the conventional rig at the BETA facility. Normally, a coil-tubing BHA is not run on the end of end of jointed pipe.

The test configuration had major reflection points at surface at the pulsation dampener and downhole between tubing and 3-1/2" drillpipe. Due to the additional reflection point between tubing and pipe, and the low damping because of the short distances, the signal was highly distorted by reflections.

After testing at BETA a question still remained: would the BCPM be able to transmit data when run on the end of a coil? This was addressed by a further post-trial test performed at the Baker Hughes Technology Center in Houston.

\section{BCPM Test with Coil Tubing}

It was decided to rent a coil tubing reel and perform a flow test with a 2-3/8” BCPM at

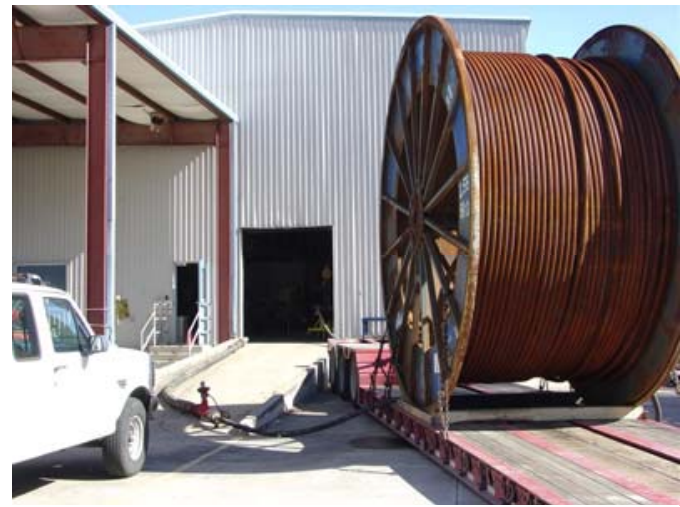

Figure 27: 7,000 foot coil inserted in flow loop. View towards test area.

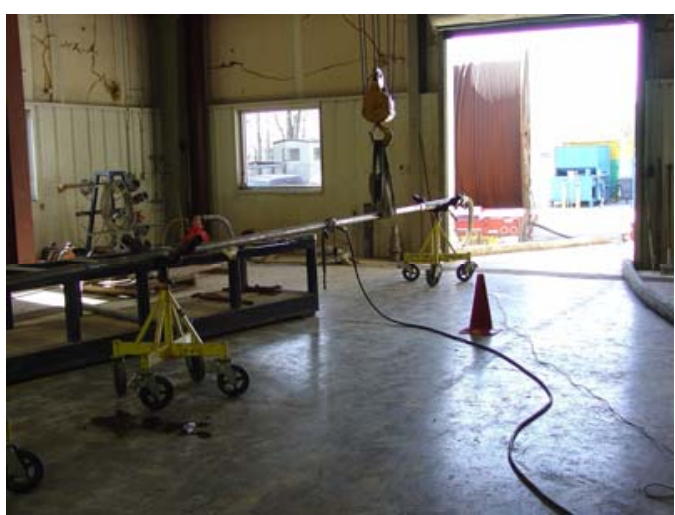

Figure 28: View from inside test area showing BCPM attached to coil 
the Baker Hughes Houston Technology Center during the 4 to 6 of December, 2007. The 7,000 foot coil was installed between the mud pump high pressure line and the $23 / 8$ " BCPM. Figure 27 shows the coil connected to the pump line and figure 28 shows the coil connected to the BCPM.

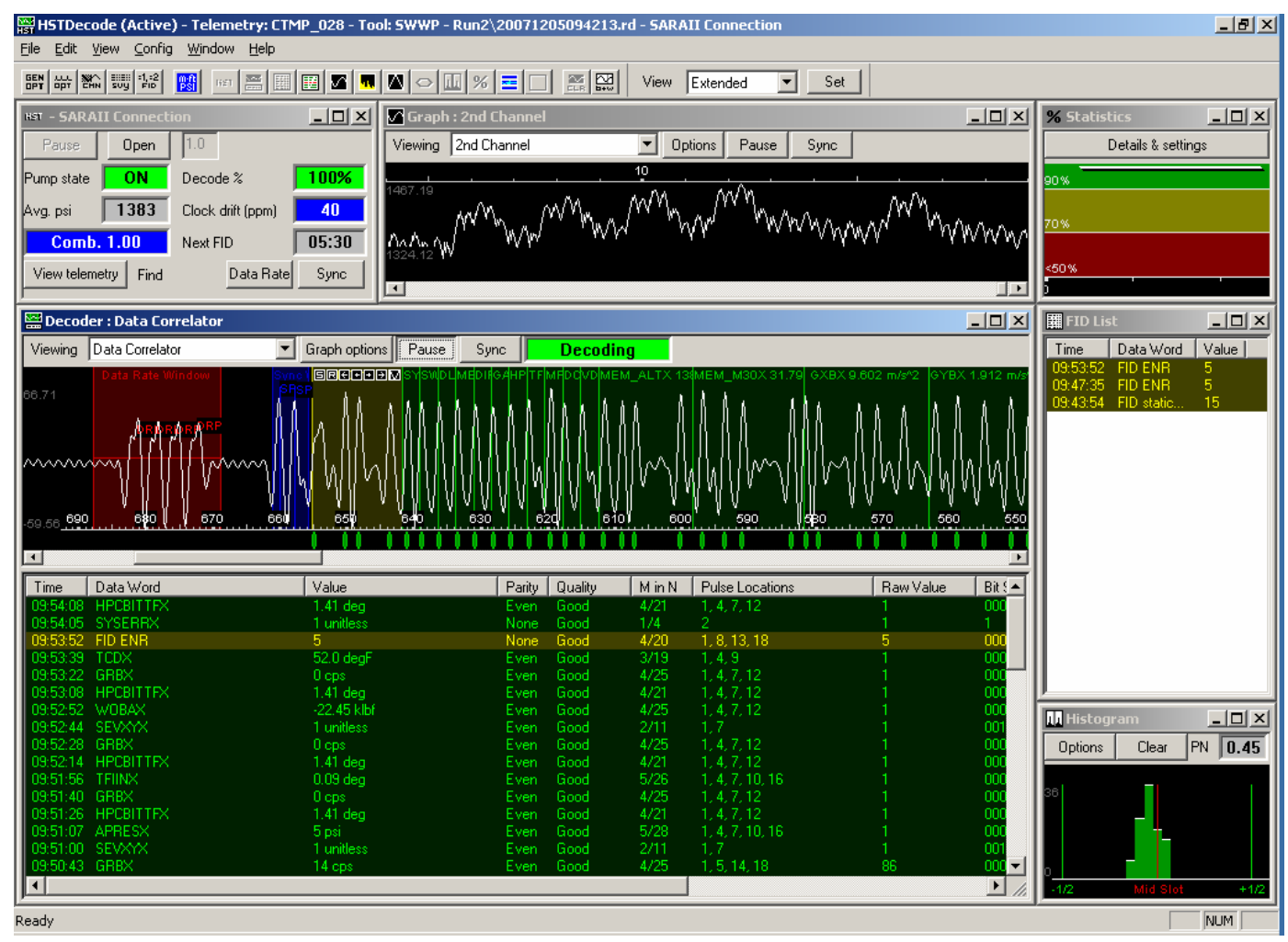

Figure 29: decoding screen shot, coil tubing test, December 4, 2007.

With a flow rate of 80 gpm, which is close to the top end of the tool's operating range, decoding was $100 \%$ with excellent pulse height of 90 psi. The well defined pulses are shown in the screenshot above, confirming that the distorted pulses measured at BETA were the results of the drillstring configuration. When run on a coil, as designed, the system transmits data as intended.

Further testing on the coil was to verify the operational flow rate range of the BCPM. The results are shown at the right and confirm previous testing; the operational range of the BCPM is 45 to 85gpm. Excellent pulse height was maintained across the operating flow range.

Final testing on December 6

\begin{tabular}{|c|c|c|}
\hline $\begin{array}{c}\text { flow rate, } \\
\text { (gpm) }\end{array}$ & decoding, \% & $\begin{array}{c}\text { pulse height } \\
\text { (psi) }\end{array}$ \\
\hline 80 & 100 & 90 \\
\hline 70 & 100 & 80 \\
\hline 60 & 100 & 70 \\
\hline 50 & 100 & $70-75$ \\
\hline 45 & 100 & $70-75$ \\
\hline 40 & 100 & $65-70$ \\
\hline 30 & tool shut down & 0 \\
\hline
\end{tabular}
addressed downlinking to the BCPM: via the Bypass Actuator, several successful downlinks were made to change data rates. 


\section{Summary Field Trial Results}

Operation of the 2-3/8” BCPM in a coil tubing BHA while drilling has been successfully demonstrated. The BCPM provided power for the entire BHA, was able to transmit data to surface under extremely difficult transmission conditions, and was able to receive down-linked information from surface. It is considered at this time that the three prototypes are ready for field operations in commercial 2-3/8” CoilTrak Bottom Hole Assemblies when an opportunity arises.

All problems observed during the field trail, such as the plugging of the first two BCPMs, and the poor transmission, have been investigated. The causes have been determined to be unrelated to the design of the BCPM. In the first instance, scale and debris within the rental tubing joints plugged the two pulsers, while in the second case the non-typical drillstring configuration produced challenging transmission conditions.

Although performed under atmospheric conditions, the operation on the end of a 7,000 foot coil has also been demonstrated. The 2-3/8” BCPM performed to specifications in this demonstration with an observed pulse height of $70-90$ psi.

During the field trial the performance of the Rib-Steering Motor (RSM) and the MultiplePropagation resistivity (MPR) with the BCPM were tested (these devices were developed as part of a previous DOE agreement). This testing was not planned as part of the project, but since the opportunity arose it was decided to proceed. The RSM and MPR performed well, but their presence in the BHA resulted in a higher than design current draw, and the RSM in particular was unable to be fully utilized. Now that the usefulness of an RSM component in a mud pulse BHA has been demonstrated it is likely that the power delivery of commercial pilot versions of the 2-3/8” BCPM will be increased.

\section{Conclusions}

Field-testing of the new 2-3/8” coiled tubing drilling BHA component, Bi-Directional Communications and Power Module (BCPM), was an overall technical success, showing that this component can support a 2-3/8" mud pulse coil tubing BHA. A mud pulse coil tubing BHA will eliminate the need for the presence of a wire in the coil, resulting in a lower cost operation.

The effective mechanical design of the tool was demonstrated by lab testing, handling of the BHA on the catwalk/rig floor and operation downhole. Also, the integration of the tool in a complex BHA was demonstrated as it powered the BHA in the field trial and supported the operation of components such as the Rib Steering Motor (RSM).

While testing to date has been considered successful, field testing of this component is not complete. It will be necessary to run in commercial operations in North America to fully validate handling and performance. However, based on the extensive field trials conducted by Baker Hughes few if any problems are anticipated. 
The development of this complex tool, from concept through successful field-testing, would not have occurred in this time frame without the support of the U.S. Department of Energy. Therefore, Baker Hughes INTEQ would like to thank the U.S. Department of Energy for partially funding the development of this prototype tool for microhole drilling.

Baker Hughes INTEQ will re-run these tools in the near future on further tests, to both further verify their performance and to accumulate operating hours. In 2009 it will then make a decision on design changes, if any, and decide on manufacturing of tools to support commercial microhole operations. 